\title{
Influenza infection in suckling mice expands an NKT cell subset that protects against airway hyperreactivity
}

\author{
Ya-Jen Chang, ${ }^{1}$ Hye Young Kim, ${ }^{1}$ Lee A. Albacker, ${ }^{1}$ Hyun Hee Lee, ${ }^{1}$ Nicole Baumgarth, ${ }^{2}$ \\ Shizuo Akira, ${ }^{3}$ Paul B. Savage, ${ }^{4}$ Shin Endo, ${ }^{5}$ Takashi Yamamura, ${ }^{6}$ Janneke Maaskant, ${ }^{7}$ \\ Naoki Kitano, ${ }^{8}$ Abel Singh, ${ }^{9}$ Apoorva Bhatt, ${ }^{9}$ Gurdyal S. Besra, ${ }^{9}$ Peter van den Elzen, ${ }^{8}$ \\ Ben Appelmelk, ${ }^{7}$ Richard W. Franck, ${ }^{10}$ Guangwu Chen, ${ }^{10}$ Rosemarie H. DeKruyff, ${ }^{1}$ \\ Michio Shimamura, ${ }^{5,6,11}$ Petr Illarionov, ${ }^{9}$ and Dale T. Umetsu ${ }^{1}$
}

\begin{abstract}
'Division of Immunology and Allergy, Children's Hospital, Harvard Medical School, Boston, Massachusetts, USA. ${ }^{2}$ Center for Comparative Medicine, University of California, Davis, California, USA. ${ }^{3}$ WPI Immunology Frontier Research Center, Osaka University, Osaka, Japan. ${ }^{4}$ Brigham Young University, Provo, Utah, USA. 5Mitsubishi Kagaku Institute of Life Sciences, Tokyo, Japan. 6 National Center of Neurology and Psychiatry, Tokyo, Japan. ${ }^{7}$ Department of Medical Microbiology, Vrje University Medical Center, Amsterdam, the Netherlands. ${ }^{8}$ Child and Family Research Institute, University of British Columbia, Vancouver, Canada. ${ }^{9}$ University of Birmingham, School of Biosciences, Birmingham, United Kingdom. 10Hunter College of CUNY, New York, New York, USA. ${ }^{11}$ University of Tsukuba, Ibaraki, Japan.
\end{abstract}

\begin{abstract}
Infection with influenza A virus represents a major public health threat worldwide, particularly in patients with asthma. However, immunity induced by influenza $A$ virus may have beneficial effects, particularly in young children, that might protect against the later development of asthma, as suggested by the hygiene hypothesis. Herein, we show that infection of suckling mice with influenza $A$ virus protected the mice as adults against allergen-induced airway hyperreactivity (AHR), a cardinal feature of asthma. The protective effect was associated with the preferential expansion of $\mathrm{CD}^{-} \mathrm{CD8}^{-}$, but not $\mathrm{CD}^{+}$, NKT cells and required T-bet and TLR7. Adoptive transfer of this cell population into allergen-sensitized adult mice suppressed the development of allergeninduced AHR, an effect associated with expansion of the allergen-specific forkhead box $\mathrm{p3}^{+}\left(\mathrm{Foxp}^{+}\right)$Treg cell population. Influenza-induced protection was mimicked by treating suckling mice with a glycolipid derived from Helicobacter pylori (a bacterium associated with protection against asthma) that activated NKT cells in a CD1d-restricted fashion. These findings suggest what we believe to be a novel pathway that can regulate AHR, and a new therapeutic strategy (treatment with glycolipid activators of this NKT cell population) for asthma.
\end{abstract}

\section{Introduction}

Bronchial asthma, a complex and heterogeneous trait, is a major public health problem, affecting nearly $10 \%$ of the general population and disproportionately affecting children. Moreover, the prevalence of asthma has increased dramatically over the past 3 decades, an increase thought to be due to changes in our environment. These environmental changes include reductions in the incidence of infectious diseases that may exert protective effects against asthma, as suggested by the hygiene hypothesis (1). While the infectious agents responsible for this relationship, and the precise mechanisms by which infectious microorganisms might protect against asthma, are very poorly understood, epidemiological studies suggest that infection with bacteria (e.g., Helicobacter pylori [refs. 2, 3], endotoxin [ref. 4], or Acinetobacter lwoffii [ref. 5]) or viruses (e.g., hepatitis A virus [refs. 6, 7]) might reduce the likelihood of developing asthma.

The role of viral infection in modulating the development of asthma is particularly complex because many different viruses affect the respiratory tract, some appearing to enhance and some to protect against the development of asthma. For example, infection with human rhinovirus in children before 3 years of age increases the later risk of developing asthma (8), while other respiratory

Authorship note: Michio Shimamura, Petr Illarionov, and Dale T. Umetsu contributed equally to this work.

Conflict of interest: The authors have declared that no conflict of interest exists. Citation for this article: J Clin Invest. 2011;121(1):57-69. doi:10.1172/JCI44845. viral infections appear to protect against the later development of asthma (9-14). However, in older individuals with established asthma, respiratory viral infection, particularly with influenza $\mathrm{A}$ virus, almost always triggers acute symptoms of asthma (15-17). These discrepancies may be due to the timing of the infection, since infection in very young children may profoundly alter the developing innate immune system in such a way as to protect against the later development of asthma, or to the specific immunological cell types activated by a given infectious agent.

To improve our understanding of the role of respiratory viral infection in children in the development of asthma, we studied a mouse model of asthma in which suckling mice were infected with the influenza A virus (H3N1), and were subsequently studied as adults for susceptibility to allergen-induced airway hyperreactivity (AHR), a cardinal feature of asthma. We found that $\mathrm{H} 3 \mathrm{~N} 1$ infection in suckling mice protected the mice as adults against allergen-induced AHR. The protective effect was associated with the preferential expansion of a subpopulation of suppressive double-negative (DN) NKT cells and was mimicked by treatment of suckling mice with several specific glycolipids, including one derived from $H$. pylori.

\section{Results}

Infection of suckling mice with $H 3 N 1$ protects against AHR. We infected suckling pups (2 weeks old) or adult mice (8 weeks old) with the influenza A/Mem71 (H3N1) virus, and 6 weeks later the mice were examined for susceptibility to OVA-induced AHR (Figure 1A). H3N1 infection 
A

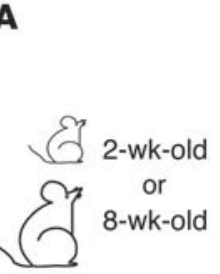

$$
\text { infection }
$$

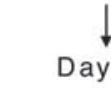

ay 0

Day 35

Day 41

Day 42

Allantoic fluid (Mock) $50 \mu \mathrm{g}$ OVA/alum, i.p. or H3N1, i.n.
$50 \mu \mathrm{g}$ OVA or AHR saline, i.n.

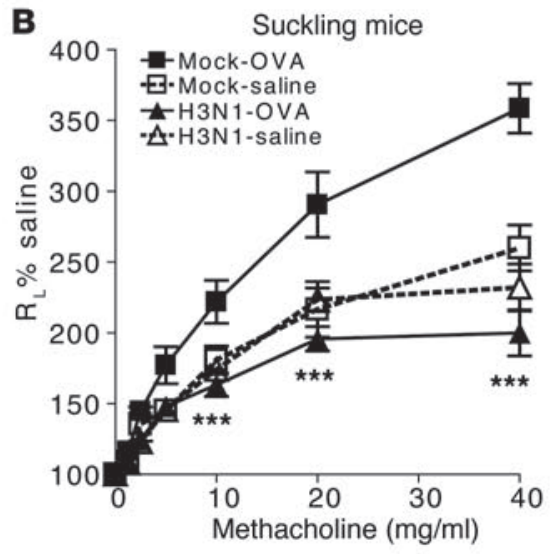

C

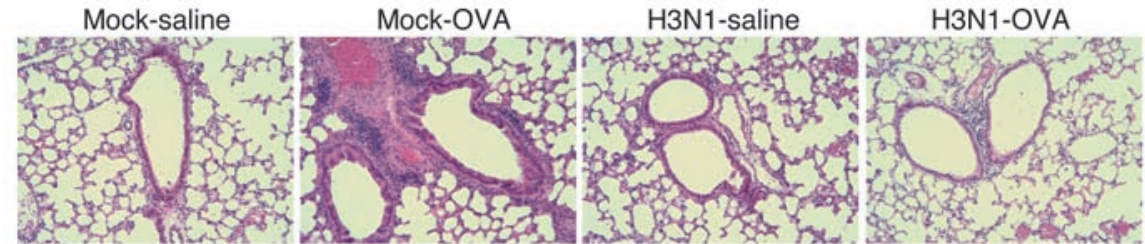

D

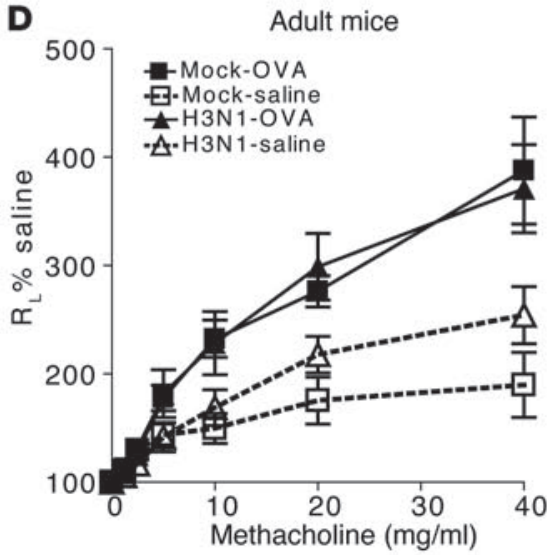

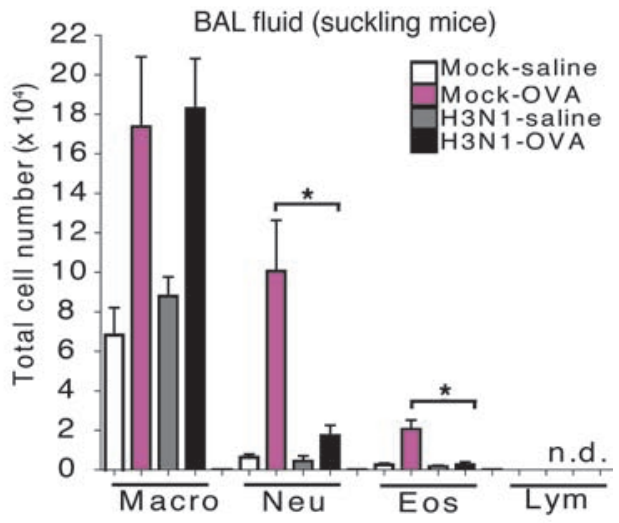

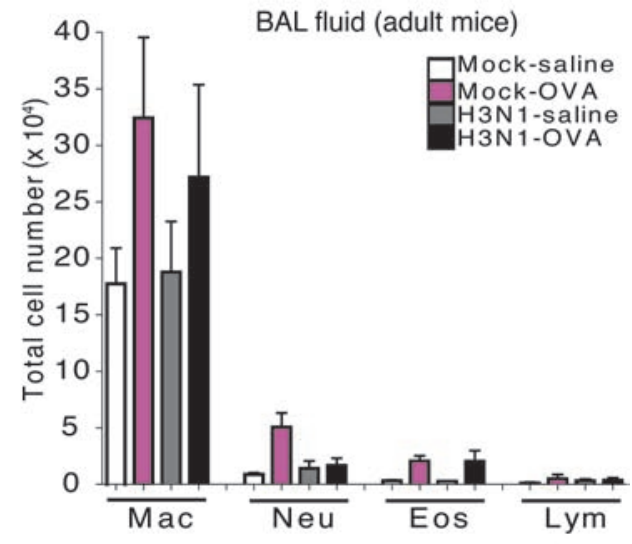

Figure 1

Infection of suckling mice with H3N1 protects the mice against $A H R$ when adults. (A) Schematic showing the protocol for OVA-induced AHR. Two-weekold (suckling) or 8 week-old (adult) mice were treated with influenza $A$ virus (H3N1) or control AF (mock infection) and assessed 6 weeks later as adults for AHR. (B) BALB/c mice ( $n=8$ per group) treated with $\mathrm{H} 3 \mathrm{~N} 1$ or $\mathrm{AF}$ at 2 weeks of age were assessed 42 days after infection for OVA-induced AHR. Changes in lung resistance $\left(R_{L}\right)$ were measured in anesthetized, tracheotomized, intubated, and mechanically ventilated mice (left panel). ${ }^{* \star *} P<0.001$ compared with mock-infected group. Cells in BAL were collected and analyzed 24 hours after the final OVA challenge (right panel). ${ }^{\star} P<0.05$ compared with mock-infected group. (C) Representative lung sections stained with H\&E (original magnification, $\times 10$ ) from mock- or H3N1-infected mice treated with saline or challenged with OVA. (D) Eight-week-old BALB/C mice ( $n=5$ per group) were infected with $\mathrm{H} 3 \mathrm{~N} 1$ or AF. Six weeks after infection, the mice were assessed for OVAinduced AHR by measuring lung resistance (left panel). Cells in BAL were collected and analyzed 24 hours after the final OVA challenge (right panel). Data are representative of 3 independent experiments. in 2-week-old mice protected the mice as adults (at 8 weeks of age) against OVA-induced AHR (Figure 1B) and airway inflammation (Figure 1, B and C). In contrast, severe OVA-induced AHR and airway inflammation developed in the mock-infected mice at 8 weeks of age. Whereas infection in 2-week-old suckling mice conferred protection, infection in 8-week-old adult mice with $\mathrm{H} 3 \mathrm{~N} 1$ did not protect against subsequent OVA-induced AHR or airway inflammation (Figure 1D).

Adoptive transfer of NKT cells cannot reconstitute OVA-induced AHR in J $\alpha 18^{-/-}$mice. Infection with a different influenza virus strain (H3N2) enhanced the ability of respiratory tolerance to prevent OVA-induced AHR (11), consistent with the idea that influenza infection is complex and can affect multiple compartments of the immune system. Because infection with the influenza A virus has been shown to directly activate NKT cells (18), which play a very important role in asthma (19), we asked whether infection with the $\mathrm{H} 3 \mathrm{~N} 1$ virus affected the function of NKT cells. We therefore purified NKT cells from mice infected with H3N1 as sucklings (42 days after infection) and adoptively transferred these cells (92\%-97\% purity; Supplemental Figure 1A; supplemental material available online with this article; doi:10.1172/JCI44845DS1) into adult OVA-sensitized, NKT cell-deficient recipients $\left(J \alpha 18^{-/-}\right.$ mice) (Figure 2A). After receiving the H3N1-exposed NKT cells, the J $\alpha 18^{-/-}$mice, which have CD1d-restricted non-invariant (but not invariant) TCR NKT cells, and which cannot develop 
A
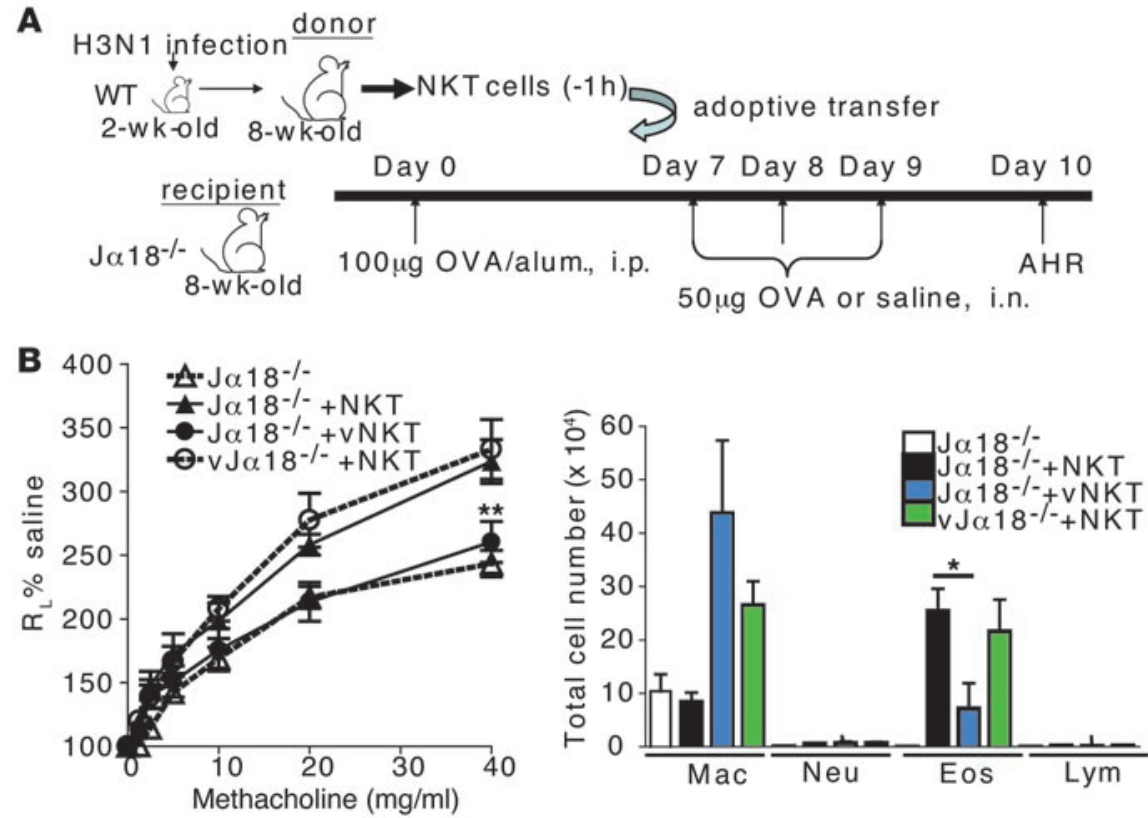

C

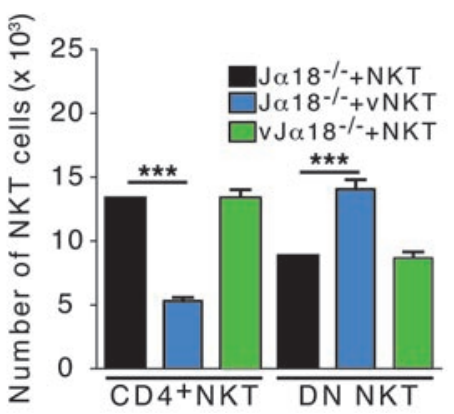

D

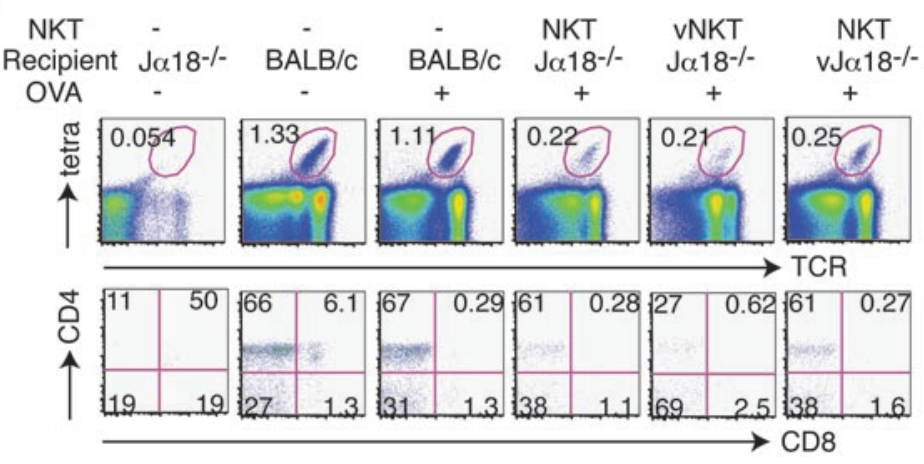

\section{Figure 2}

Adoptive transfer of H3N1-exposed NKT cells fails to reconstitute OVA-induced AHR. (A) Schematic showing the protocol for adoptive transfer of NKT cells to OVA-immunized $J \alpha 18^{-/-}$recipients. The donor mice were infected with H3N1 or mock infected at 2 weeks of age. Six weeks after infection, NKT cells were purified and adoptively transferred into OVA-sensitized $J \alpha 18^{-/-}$mice, which were then challenged with OVA and assessed for AHR. (B) Adoptive transfer of H3N1-exposed NKT cells (VNKT) to J $\alpha 18^{-/-}$mice failed to reconstitute OVA-induced AHR (measured as lung resistance in response to methacholine challenge) (left panel). Adoptive transfer of NKT cells from mock-infected mice (NKT) fully reconstituted AHR. H3N1 infection at 2 weeks of age of $J_{\alpha} 18^{---}$mice $\left(\mathrm{V} J \alpha 18^{---}\right)$and reconstitution at 8 weeks of age with NKT cells from mock-infected mice did not protect against AHR ( $n=8-10$ per group). BAL fluid was collected and analyzed (right panel). ${ }^{*} P<0.05$ and ${ }^{* \star} P<0.01$, compared with $J \alpha 18^{--}+$NKT group. (C and D) Lung cells were isolated from the recipients after measurement of AHR, and the absolute numbers (C) and percentages (D) of lung CD4+ or CD4-CD8- (DN) NKT subsets were assessed by FACS. Upper panels show dot plots for NKT cells in lung leukocytes. After gating on the NKT cells, the cells were analyzed for CD4 and CD8 (lower panels). ${ }^{* \star *} P<0.001$ compared with WT NKT group. Data are representative of 3 independent experiments.

allergen-induced AHR unless reconstituted with functional invariant TCR NKT cells (20-22), failed to develop OVA-induced AHR (Figure 2B). In contrast, transfer of NKT cells from mock-infected mice to $J \alpha 18^{-/-}$mice fully reconstituted AHR. Moreover, H3N1 infection in 2-week-old $J \alpha 18^{-/-}$suckling mice ( $v J \alpha 18^{-/-}$mice) and later reconstitution (at 8 weeks of age) with NKT cells from mockinfected mice did not prevent OVA-induced AHR (Figure 2B), indicating that early exposure of all of the non-NKT cells in $J \alpha 18^{-/-}$ mice (e.g., conventional $\mathrm{CD}^{+}{ }^{+}$and $\mathrm{CD}^{+}{ }^{+} \mathrm{T}$ cells) to $\mathrm{H} 3 \mathrm{~N} 1$ was not effective in preventing AHR. Finally, in the lungs of mice receiving the H3N1 virus-exposed NKT cells (42 days after infection), sig- nificantly more CD4-CD8- (DN) NKT cells and significantly fewer $\mathrm{CD}^{+}{ }^{+}$NKT cells were present (Figure 2, C and D), suggesting that $\mathrm{H} 3 \mathrm{~N} 1$ infection of 2-week-old suckling mice reduced the inflammatory function of the NKT cells, possibly by altering the $\mathrm{CD}^{+}$ versus DN NKT cell subset proportions.

$H 3 N 1$ infection accelerates the expansion of pulmonary NKT cells in suckling mice. In 2-week-old naive suckling mice, few NKT cells were present in the lungs, although this number increased normally to adult levels over a 6 -week period (Figure 3A). Importantly, H3N1 infection but not mock infection in suckling mice greatly accelerated the expansion of the pulmonary NKT cell numbers (Figure 3B). 

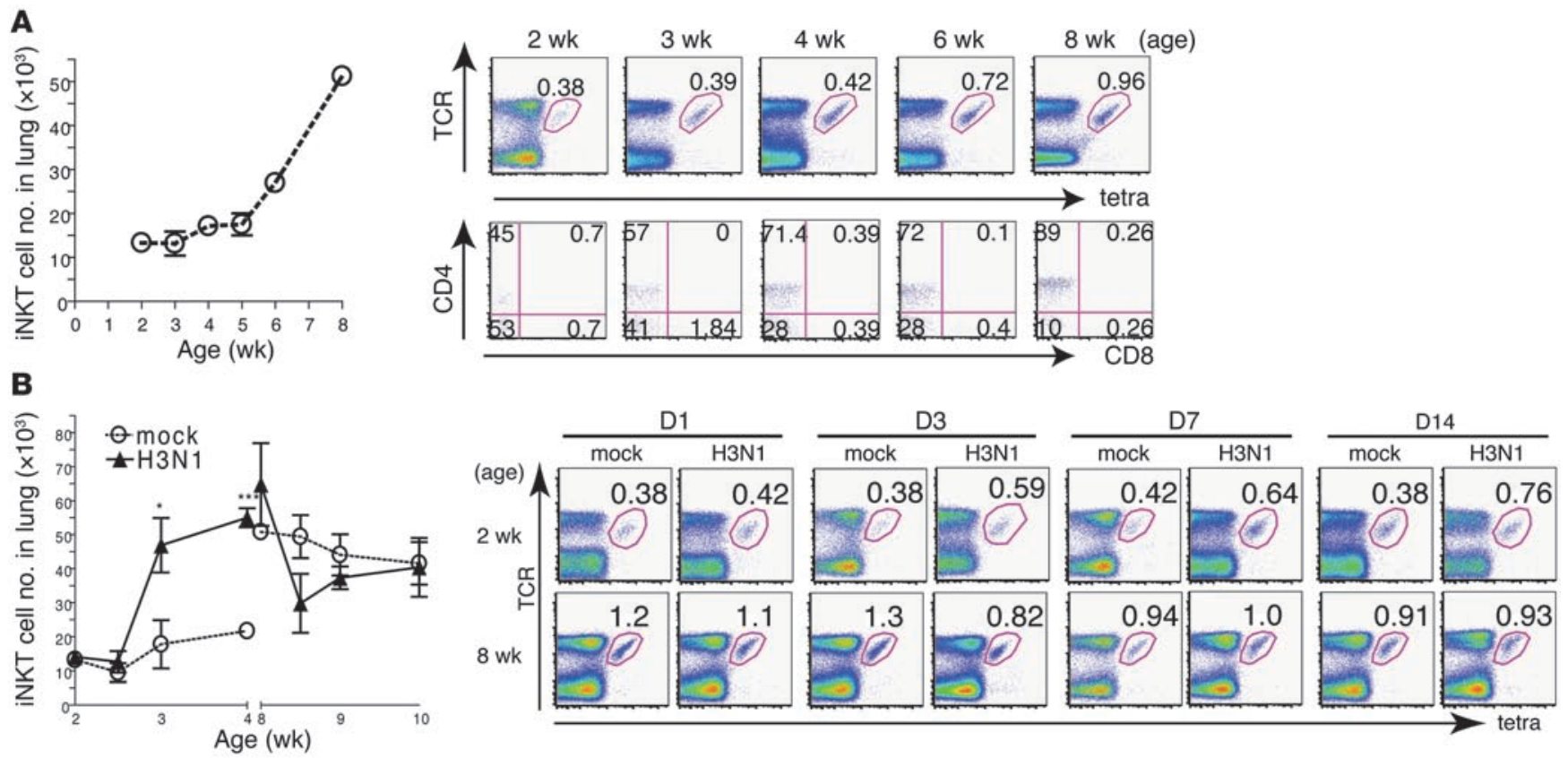

C Day 1 and 14 after infection (suckling mice)
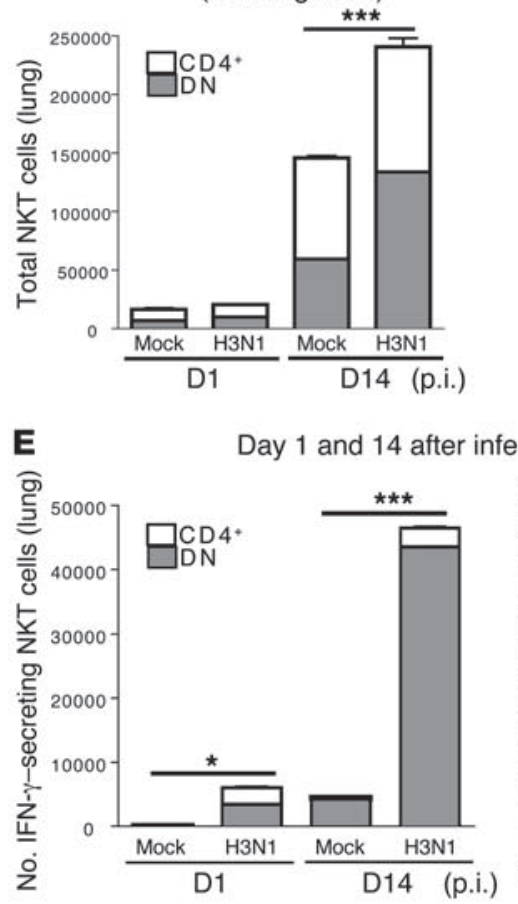

F Day 42 after infection

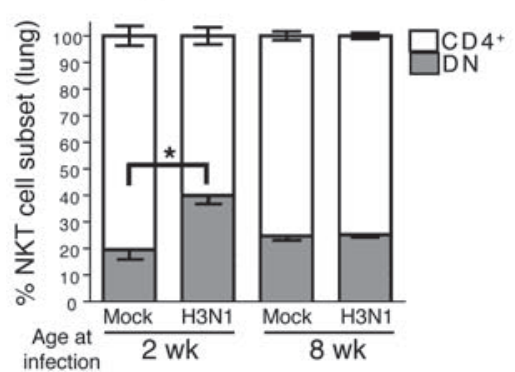

D Day 1 and 14 after infection (suckling mice)
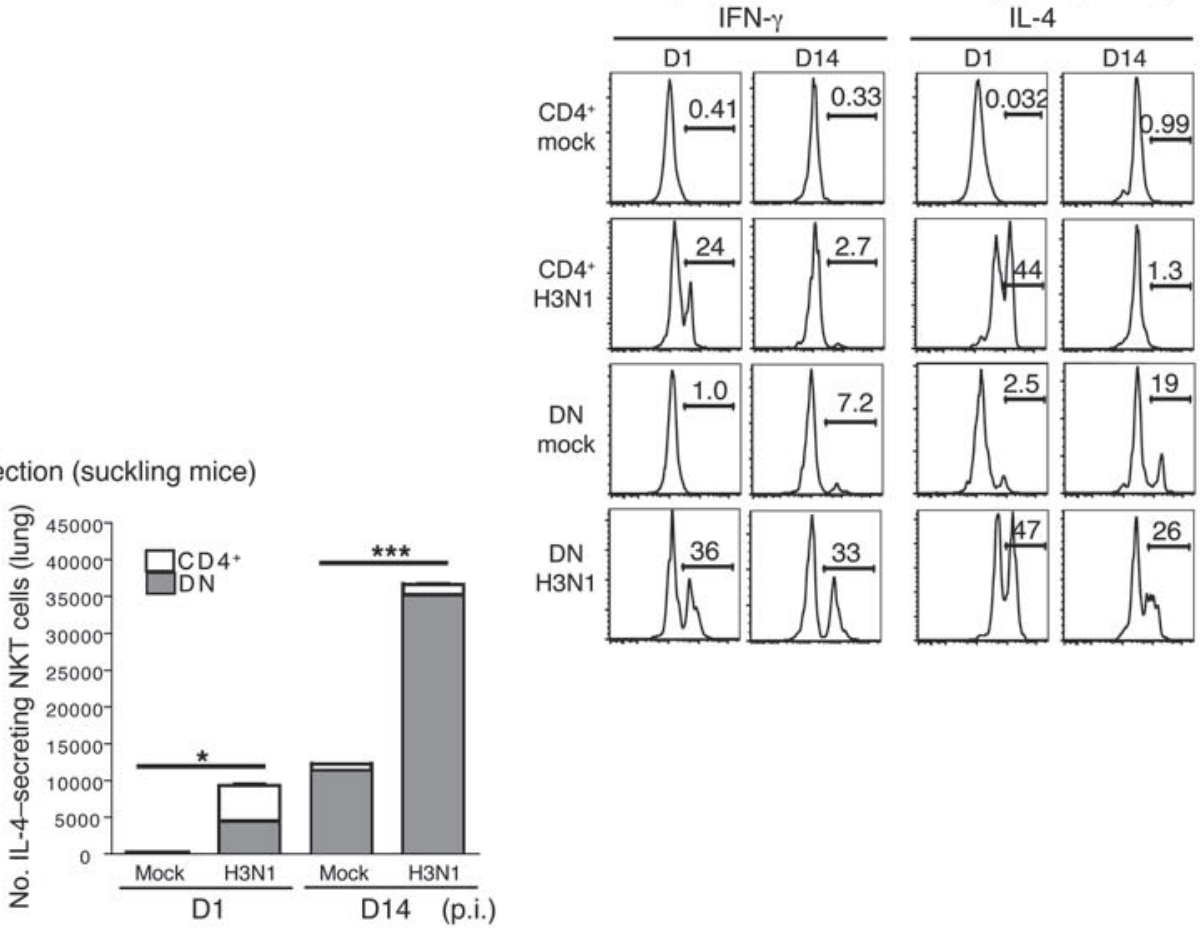

G

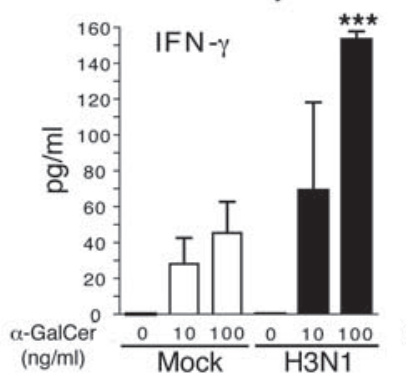

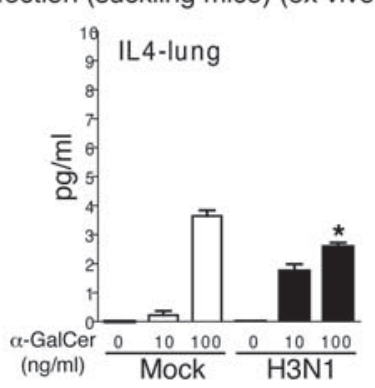

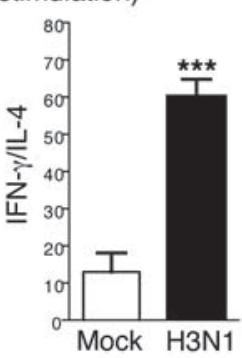




\section{Figure 3}

H3N1 infection in 2-week-old mice alters the phenotype of the NKT cells. (A) Lung cells were isolated over a 6-week period and analyzed for NKT cells. Left: Absolute numbers of lung NKT cells. Right: Percentage of NKTs (top) in lung leukocytes. NKT cells were analyzed for CD4 and CD8 (bottom). (B) Left: BALB/c mice ( $n=3 /$ group) were infected with H3N1 or AF at 2 or 8 weeks of age, and lung NKT cells were assessed over 2 weeks. Right: Percentage of NKT cells in lungs of 2-week-old and 8-week-old mice. (C) Two-week-old BALB/c mice were mock infected or infected with $\mathrm{H} 3 \mathrm{~N} 1$, and pulmonary CD4 ${ }^{+} \mathrm{NKT}$ and DN NKT cell numbers were assessed on days 1 and 14 after infection. (D and E) NKT cells from $\mathbf{C}$ were assessed for CD4, IFN- $\gamma$, and IL-4 expression (D) and absolute numbers quantified (E). (F) BALB/C mice ( $n=4-5$ /group) were infected with H3N1 or mock infected at 2 or 8 weeks of age, and lung samples were taken 42 days later to assess NKT cell subsets. One of 2 independent experiments is shown. (G) Two-week-old BALB/c mice were infected with H3N1 or mock infected. After 42 days, lung cells were harvested and stimulated ex vivo with vehicle or $\alpha$-GalCer for 96 hours. IFN- $\gamma$ and IL- 4 in supernatants from triplicate wells were determined by ELISA and the IFN- $\gamma / \mathrm{IL}-4$ ratio calculated. ${ }^{\star} P<0.05,{ }^{\star \star \star} P<0.001$ compared with mock infection.

In contrast, $\mathrm{H} 3 \mathrm{~N} 1$ infection in adult mice had little effect on pulmonary NKT cell numbers. In fact, H3N1 infection in the adult mice transiently reduced the number of NKT cells, possibly due to activation-induced TCR downregulation (Figure 3B). In 2-weekold suckling naive mice, approximately $50 \%$ of the pulmonary NKT cells were $\mathrm{CD}^{+}$, and over time this fraction increased such that in 8 -week-old adult naive mice, $89 \%$ of the pulmonary NKT cells were $\mathrm{CD}^{+}$(dot plots in Figure 3A). However, H3N1 infection of suckling mice preferentially increased the number of DN NKT cells by day 14 after infection (Figure $3 \mathrm{C}$ ). Both $\mathrm{CD}^{+}$and DN NKT cells from the suckling mice secreted IFN- $\gamma$ on day 1 of infection, but 14 days after infection only $\mathrm{DN}$ but not $\mathrm{CD} 4^{+}$pulmonary NKT cells continued to secrete IFN- $\gamma$ (and IL-4), as assessed with intracellular staining without in vitro restimulation (Figure 3D). Thus, 14 days after infection the great majority of cytokine-secreting cells in the lungs were DN NKT cells (Figure 3E).

Analysis of the mice 42 days after H3N1 infection showed that the proportion of DN versus $\mathrm{CD} 4^{+} \mathrm{NKT}$ cells in the lungs doubled, whereas 42 days after $\mathrm{H} 3 \mathrm{~N} 1$ infection in 8-week-old mice, there was no effect on the proportion of DN NKT cells in the lungs (Figure $3 \mathrm{~F})$. Assessment of the cytokine profile of NKT cells 42 days following infection after ex vivo stimulation with $\alpha$-galactosylceramide ( $\alpha$-GalCer, which specifically activates NKT cells) demonstrated increased IFN- $\gamma$ but not IL-4 production by the H3N1-exposed NKT cells (Figure 3G), resulting in a greatly increased IFN- $\gamma / \mathrm{IL}-4$ ratio (Figure $3 \mathrm{G}$ ). These results suggested that $\mathrm{H} 3 \mathrm{~N} 1$ infection in suckling mice preferentially expanded a unique NKT cell population in the lungs that, by day 42 , preferentially produced IFN- $\gamma$ but not IL-4 and was associated with a reduced expression of CD4.

Adoptive transfer of H3N1-exposed NKT cells suppresses AHR and induces Treg cells. While the H3N1-exposed NKT cells (vNKT) could not induce AHR when transferred into $J \alpha 18^{-/-}$mice (Figure 2 ), they were not anergic, but instead potently suppressed OVA-induced AHR (Figure 4, A and B) and inflammation (Figure 4C), as assessed by adoptive transfer 42 days after infection into adult WT OVAsensitized mice. In contrast, NKT cells from mock-infected mice (WT NKT) (Figure 4, B and C) or from adult mice infected with H3N1 (data not shown) did not suppress OVA-induced AHR. The proportion of DN NKT cells in the lungs of mice receiving the
H3N1 virus-exposed NKT cells was increased (Figure 4D), consistent with the idea that $\mathrm{H} 3 \mathrm{~N} 1$ infection in suckling mice preferentially expands a subpopulation of DN NKT cells.

To more clearly demonstrate that the DN NKT cell subpopulation was responsible for the suppression of $\mathrm{AHR}$, we purified $\mathrm{CD}^{+}$ and DN NKT cell subpopulations from the spleens of mice (purity 96\%-99\%) (Supplemental Figure 1C), which had been infected with H3N1, and adoptively transferred these cells into OVA-sensitized mice. Figure 4E shows that the DN but not the $\mathrm{CD}^{+} \mathrm{NKT}$ cell population suppressed AHR that developed on challenge of the mice with OVA, confirming that the H3N1-exposed DN NKT cell population was responsible for this effect.

The suppression of AHR by the transferred H3N1-exposed NKT cells was associated with a $50 \%$ increase in the number of natural Foxp $3^{+}$Treg cells and with a 300\% increase in the number of adaptive OVA-specific Foxp $3^{+}$Treg cells in the lungs (assessed by transferring DO11.10 Tg OVA-specific Foxp3- $\mathrm{T}$ cells from DO11.10 Tg $\times \mathrm{Rag}^{-1}$ - mice), compared with when NKT cells from mock-infected mice were transferred (Figure 4F). Furthermore, the inhibitory effect of the NKT cells exposed to H3N1 was reversed by treatment of the recipient mice with an anti-CD25 mAb (Figure $4 \mathrm{G}$ ). These results together indicated that H3N1-exposed NKT cells could suppress the development of experimental asthma, and that natural and adaptive Treg cells might mediate the suppressive effects of the NKT cell population.

We found a similar suppressive NKT cell population in V $\alpha 14$ TCR Tg mice. Adult V $\alpha 14$ TCR transgenic mice have a 5- to 10fold increase in the number of NKT cells in the spleen, of which the majority (53\%) are DN NKT cells (Supplemental Figure 1B), whereas in WT BALB/c mice, only $11 \%$ of the splenic NKT cells are DN (Supplemental Figure 1B). Adoptive transfer of NKT cells purified from Va14 TCR Tg mice into adult WT OVA-sensitized BALB/c mice greatly suppressed the development of OVA-induced AHR and airway inflammation (Figure 4, H-J). Transfer of V 14 TCR Tg NKT cells was also associated with a $50 \%$ increase in the number of natural Foxp $3^{+}$Treg cells and in a 300\% increase in the number of adaptive OVA-specific Foxp $3^{+}$Treg cells (assessed by transfer of DO11.10 Tg OVA-specific cells), compared with transfer of naive (WT) NKT cells (Figure 4F). These results suggest that NKT cells in Va14 Tg mice were similar to NKT cells from suckling mice exposed to $\mathrm{H} 3 \mathrm{~N} 1$, in that they had suppressive activity for allergen-induced AHR.

The protective effect of H3N1 infection depends on TLR7 and T-bet. Since influenza A virus is a single-stranded RNA (ssRNA) virus, and since T-bet participates in IFN- $\gamma$ production and in NKT cell maturation (23), we infected 2-week-old $\mathrm{Tlr} 7^{-1-} \mathrm{Tbet}^{-1-}$ mice and control WT BALB/c mice with the $\mathrm{H} 3 \mathrm{~N} 1$ virus. Six weeks later, the mice were examined for OVA-induced AHR (protocol shown in Figure $5 \mathrm{~A}$ ). Whereas $\mathrm{H} 3 \mathrm{~N} 1$ infection in suckling WT mice protected against subsequent OVA-induced AHR and airway inflammation (Figure 5, B and C), H3N1 infection in suckling Tlr $7^{-1-}$ or suckling Tbet $^{-1}$ mice failed to protect against, and even exacerbated, OVA-induced AHR and airway inflammation. Furthermore, the ratio of IFN- $\gamma$ production to IL-4 production in NKT cells from $\operatorname{Tlr} 7^{-1-}$ mice was reduced (Supplemental Figure 2D), while IFN- $\gamma$ was reduced and IL-13 and IL-17 production increased in NKT cells in Tbet ${ }^{-1}$ mice compared with WT mice (Supplemental Figure 2, A and E). (Note that Tbet ${ }^{-/}$mice have reduced numbers of NKT cells, particularly in the liver [ref. 23] but have significant numbers of pulmonary NKT cells compared with WT mice [ref. 24]). 
A
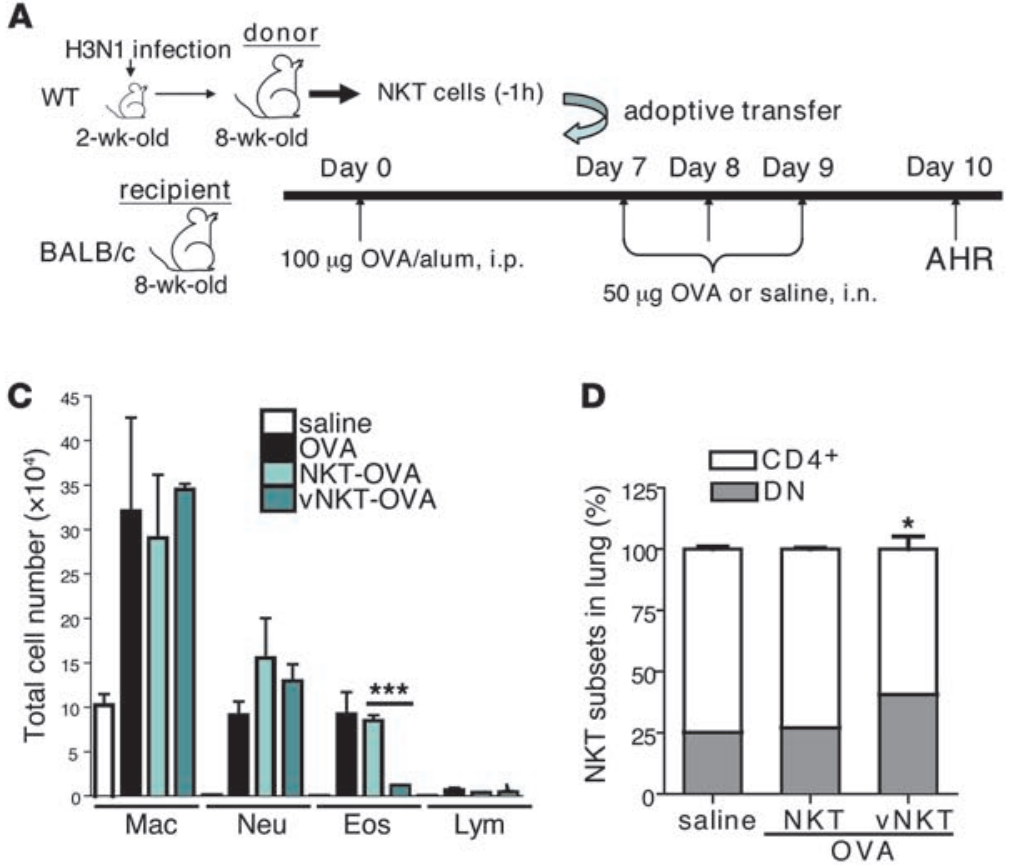

F

F Natural Tregs
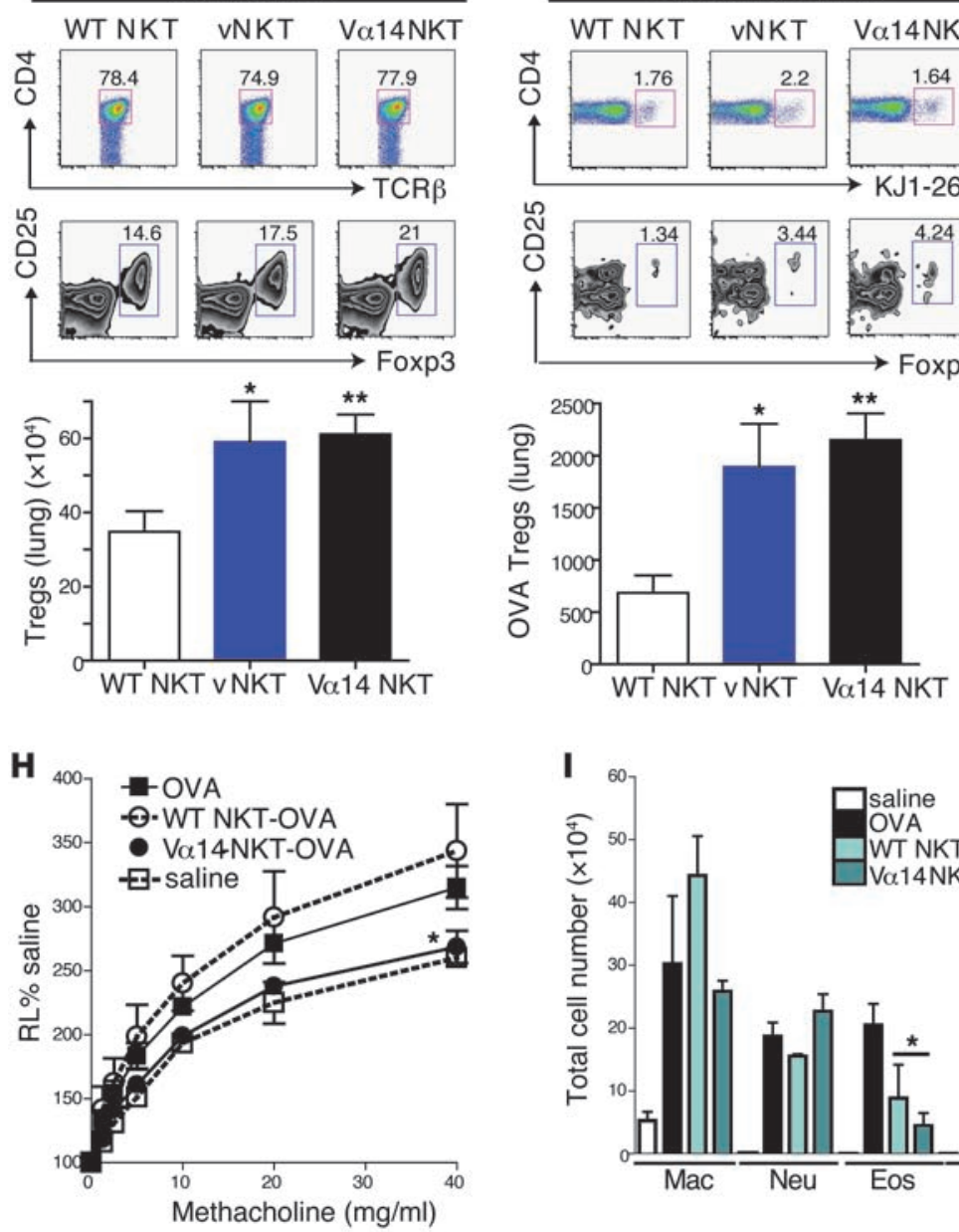
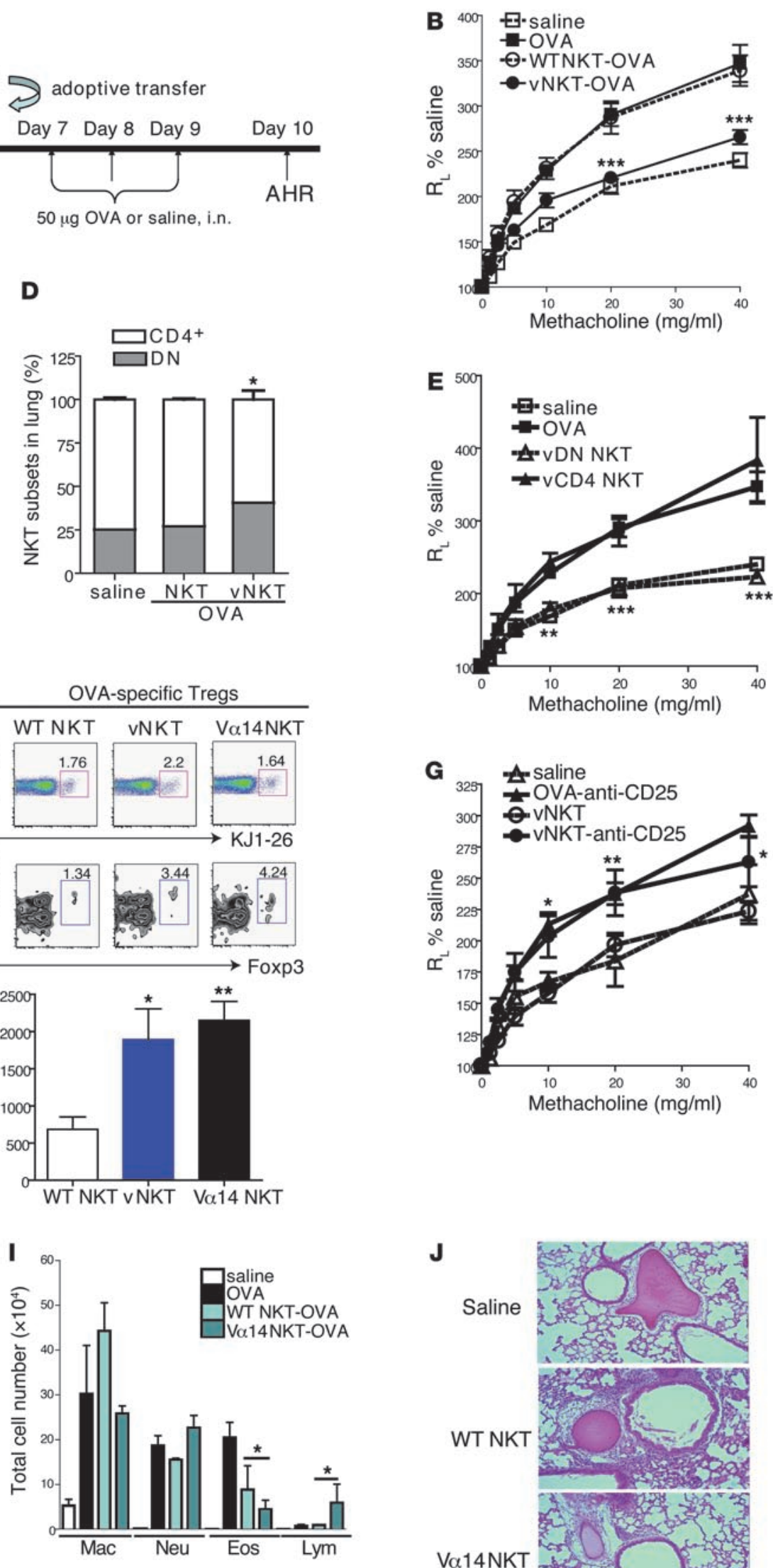

J

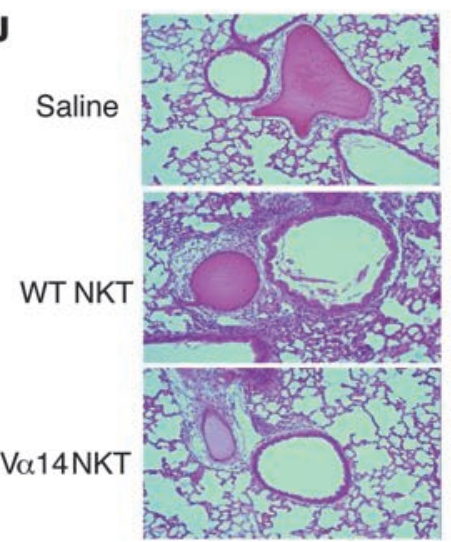




\section{Figure 4}

H3N1-exposed NKT cells suppress AHR and increase OVA-specific Tregs. (A) Protocol for adoptive transfer of NKT cells. (B and C) Lung resistance was measured in recipient mice (B; $n=15$ /group) and $\mathrm{BAL}$ cells collected (C). (D) Relative numbers of CD4+ versus DN NKT cells in recipients' lungs were assessed (E) H3N1-exposed CD4-CD8-NKT (vDN NKT) or CD4+NKT (vCD4 NKT) cells were purified and transferred as in A. Lung resistance was measured in recipient mice ( $n=5 /$ group). (F) Eight-week-old WT BALB/c mice received $5 \times 10^{4}$ D011.10 Rag $\mathrm{R}^{-1-} \mathrm{T}$ cells and were sensitized with OVA/alum. Seven days later, NKT cells from WT BALB/c, V $\alpha 14$ tg, or H3N1-infected mice were adoptively transferred into OVA-sensitized mice. After OVA challenge, the numbers of natural Tregs $\left(\mathrm{CD} 4^{+} \mathrm{C} 25^{+} \mathrm{Foxp} 3^{+}\right)$and adaptive OVA antigen-specific Tregs (CD4+ $\left.{ }^{+} \mathrm{CD} 25^{+} \mathrm{Foxp}^{+} \mathrm{KJ} 1-26^{+}\right)$were determined. Absolute cell numbers were calculated ( $n=5 /$ group). (G) Eightweek-old WT BALB/c recipients were depleted of Tregs through injections of anti-CD25 mAb (clone PC61; $0.5 \mathrm{mg}$ ) and assessed as in A ( $n=5$ /group). (H and I) NKT cells from WT or V $\alpha 14 \mathrm{Tg}$ were transferred to OVA-sensitized BALB/c mice ( $n=4-6 /$ group), which were assessed as in $\mathbf{A}(\mathbf{H})$, and BAL cells were analyzed (I). (J) Representative lung sections from recipients described in $\mathbf{H}$ were $\mathrm{H} \& \mathrm{E}$ stained (original magnification, $\times 10$ ). Data represent $2-3$ independent experiments. ${ }^{*} P<0.05,{ }^{* *} P<0.01,{ }^{* *} P<0.001$ versus WT NKT-OVA (B-D), OVA $(E)$, WT NKT (F, H, and I), and OVA-VNKT (G).

As noted above (Figure 3F), protection against AHR was associated with an increase in the number of DN NKT cells following H3N1 infection in WT mice, which did not occur in $T l r 7^{-1-}$ or $\mathrm{Tbet}^{-/-}$mice (Figure 5D). Moreover, adoptive transfer of NKT cells purified 6 weeks after $\mathrm{H} 3 \mathrm{~N} 1$ infection of WT, but not Tlr $7^{-/-}$or Tbet ${ }^{/-}$mice, into OVA-sensitized WT BALB/c mice suppressed OVA-induced AHR and airway inflammation (Figure 5, E and F). Taken together, these results indicate that protection by H3N1-exposed NKT cells against AHR depends on TLR7 and T-bet.

Induction of protection with $\alpha-C-G$ alCer and a glycolipid from $H$. pylori. Since NKT cells appeared to mediate the effects of H3N1 infection, we examined a panel of glycolipids that specifically activate NKT cells for the capacity to replicate the beneficial effects of H3N1 infection. We first examined the effects of $\alpha$-C-GalCer, a synthetic $\mathrm{C}$-glycoside analog of $\alpha$-GalCer that preferentially induces IFN- $\gamma$ but not IL-4 synthesis (25-27). Treatment of suckling mice with $\alpha$-C-GalCer $(5 \mu \mathrm{g})$, but not $\alpha$-GalCer, which induces production of both IFN- $\gamma$ and IL-4, protected the mice as adults (42 days later) from the development of OVA-induced AHR (Figure 6A). The protective effect was dependent on T-bet, since Tbet $/-$ mice were not protected by treatment with $\alpha$-C-GalCer (Figure 6B). Moreover, adoptive transfer of NKT cells exposed to $\alpha$-C-GalCer protected recipients against the development of AHR and airway inflammation (Figure 6C).

We also found a second glycolipid, PI57, a cholesterol-derived lipid from $H$. pylori (28), that could protect against the development of AHR (Figure 6D). H. pylori, a bacteria that colonizes the stomach (29) and is associated with protection against asthma (2, 3 ), produces cholesteryl $\alpha$-glucosides (30), including cholesteryl 6-O-acyl $\alpha$-glucoside (AGlc-Chol) (Supplemental Figure 4), which was chemically synthesized (PI57) (Figure 6D). PI57, when administered i.p. to 2-week-old mice, increased the total number of NKT cells, particularly the number of DN NKT cells, found in the lung 2 weeks later (Figure 6, E and F). In contrast, treatment with $\alpha$-GalCer increased both $\mathrm{CD}^{+}$and DN NKT cells in the lungs. Importantly, treatment of 2-week-old mice with PI57 (50 or $100 \mu \mathrm{g}$ ) (Figure 6G) protected the mice from the development of OVA-induced AHR, induced 6 weeks after the glycolipid treatment. On the other hand, treatment of 2-week-old mice with PBS30, a lipid present in the cell walls of Sphingomonas bacteria $(31,32)$, failed to protect the mice from OVA-induced AHR (Figure 6H). Moreover, adoptive transfer of NKT cells from PI57-treated, but not vehicle-treated, 2-weekold mice (harvested 6 weeks after treatment) into OVA-sensitized WT mice, suppressed AHR and airway inflammation (Figure 6, I and J). Transfer of NKT cells from $\alpha$-GalCer-treated mice reduced AHR slightly, but this was not statistically significant (Supplemental Figure 3A). The production of IFN- $\gamma$ by the NKT cells was important, since the protective effect of PI57, like that of H3N1 and $\alpha$-C-GalCer, was dependent on T-bet, since PI57 treatment of 2-week-old Tbet ${ }^{/-}$mice did not protect against subsequent OVAinduced AHR (Supplemental Figure 3B). These results together suggest that a subset of NKT cells that can be specifically activated by some but not all glycolipid antigens, and that preferentially produces IFN- $\gamma$, mediates the protective effects of H3N1 infection.

PI57 is a CD1d-dependent NKT cell antigen. To demonstrate that PI57, like $\alpha$-C-GalCer, can directly activate NKT cells, we showed that PI57, when added to cultures of NKT cell lines plus DCs, induced the production of IFN- $\gamma$ in a CD1d-restricted manner, since cytokine production was blocked by anti-CD1d mAb (Figure 7A). In addition, PI57 induced higher levels of IFN- $\gamma$ and less IL-4 in NKT cell lines compared with PBS30 (from Sphingomonas) or $\alpha$-GalCer, and did so in a CD1d-restricted manner, since DCs from $C d 1 d^{-/}$mice failed to support PI57-induced cytokine production (Figure 7B). Furthermore, the PI57 response occurred by direct activation of NKT cells, since PI57 induced cytokine production in NKT cell lines with DCs from $M y d 88^{-/-}$or Trif/- mice (Figure 7B), and since 3 different NKT cell hybridomas derived from $V \alpha 14$ NKT cells but not from V $14^{-} \mathrm{T}$ cells produced IL-2 in response to immobilized recombinant CD1d previously loaded with PI57 but not with PI56, a control glycolipid (Figure 7C). Moreover, CD1d tetramers loaded with PI57 stained $10 \%-23 \%$ of NKT cells in an NKT cell line (Figure 7D). Of the PI57-CD1d tetramer ${ }^{+}$cells, 92\% were $\mathrm{CD}^{-}$(DN) (data not shown). This strongly suggests that PI57 bound to CD1d was directly recognized by the TCR of a population of NKT cells. Finally, human NKT cells were also activated by PI57, since NKT cells lines (Figure 7E) as well as a V $224^{+} \mathrm{NKT}$ cell clone (BM2a.3) (Figure 7F) responded to this glycolipid. The response was also directly induced, since plate-bound CD1d loaded with PI57 induced IFN- $\gamma$ in BM2a.3 cells (Figure 7G). Taken together, these results indicated that both mouse and human NKT cells were directly activated by PI57, an H. pylori glycolipid, in a CD1d-restricted manner.

\section{Discussion}

Herein, we showed that infection of 2-week-old pups with influenza A virus $\mathrm{H} 3 \mathrm{~N} 1$ protected against the subsequent development of allergen-induced AHR, whereas infection of adult (8-week-old) mice with $\mathrm{H} 3 \mathrm{~N} 1$ did not protect against the subsequent development of AHR. The protective effect H3N1 in suckling mice was associated with the maturation and expansion of a specific subset of NKT cells, which suppressed the development of allergeninduced AHR, demonstrated by adoptive transfer of these NKT cells into normal allergen-sensitized adult mice. The protective NKT cell subset required T-bet, as the NKT cells had to be derived from T-bet ${ }^{+}$mice; this subset also produced IFN- $\gamma$ and was present in NKT cell populations enriched for DN (CD4-) NKT cells. Adoptive transfer of the protective NKT cell population was associated 
A

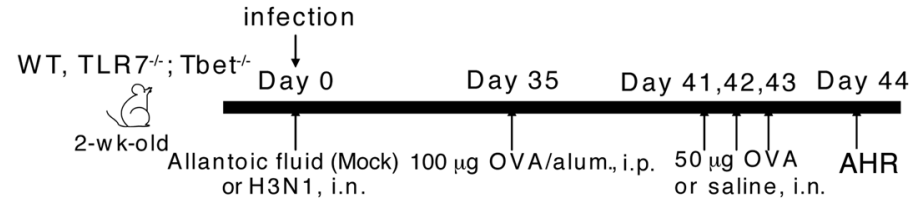

B
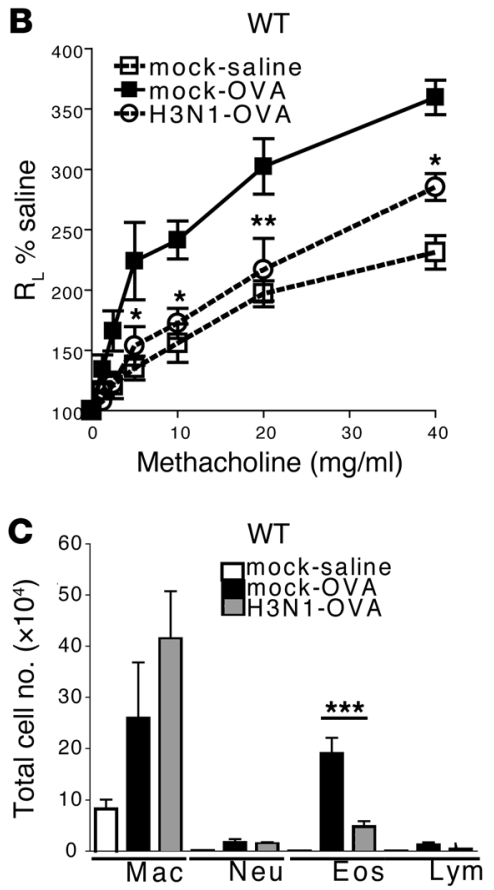

D

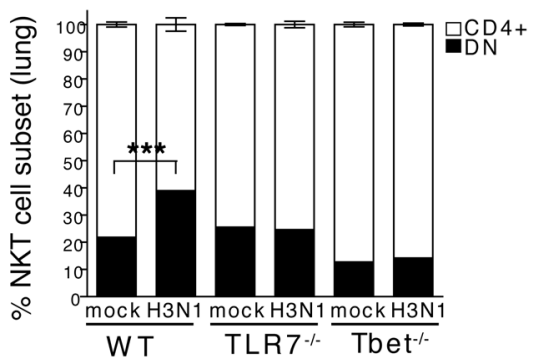

TIr7--
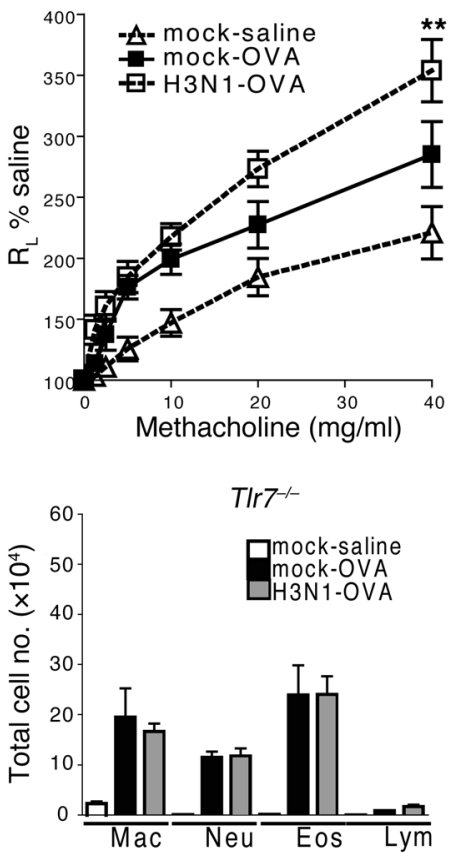

Tbet $^{-}$
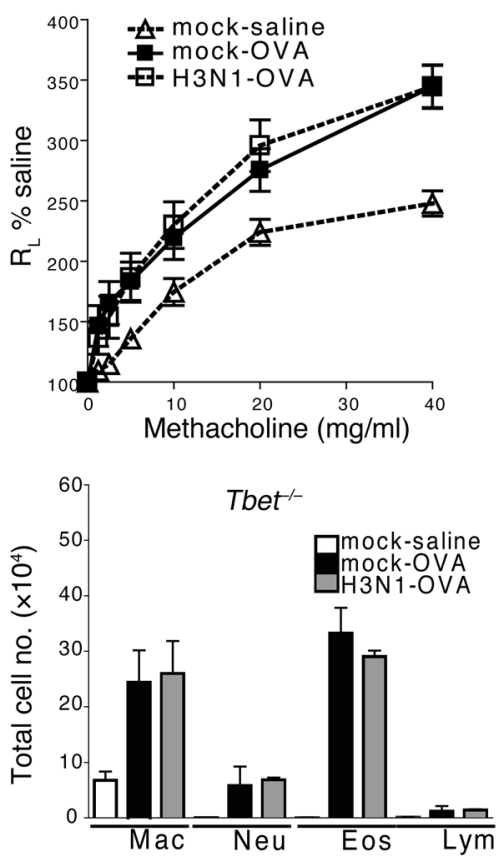

E

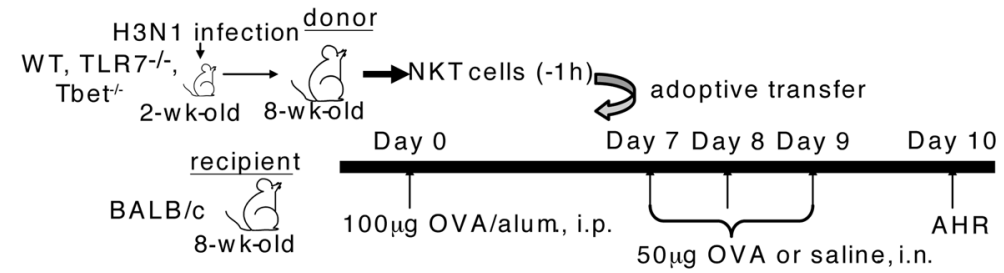

$\mathbf{F}$
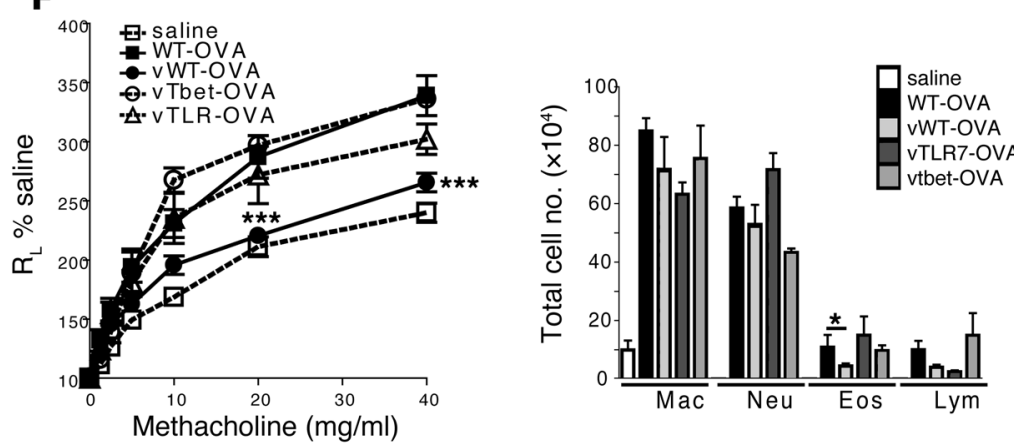

Figure 5

The protective effect of H3N1 infection depends on TLR7 and T-bet. (A) Schematic showing the protocol for WT, TIr7 $7^{-/-}$, or Tbet ${ }^{+-}$mice infected at 2 weeks of age with H3N1 virus or mock infected and examined for OVA-induced AHR at 8 weeks of age $(n=4-6$ per group). (B) Lung resistance was measured. ${ }^{*} P<0.05,{ }^{* \star} P<0.01,{ }^{* \star *} P<0.001$ compared with the mock-OVA group. (C) BAL cells from B were collected. (D) WT, TIr7 ${ }^{-l-}$, or $\mathrm{Tbet}^{-/}$mice were infected with $\mathrm{H} 3 \mathrm{~N} 1$ or mock at 2 weeks of age, and lung samples were taken 42 days later to asses for NKT cell subsets. ${ }^{* \star *} P<0.001$ compared with the mock group. (E) Schematic showing the adoptive transfer of NKT from virus-infected WT, TIr $7^{-/-}$, or Tbet ${ }^{-1-}$ mice to OVA-sensitized BALB/c recipients ( $n=4-6$ per group). The donor mice were infected with H3N1 or mock-infected at 2 weeks of age. NKT cells were purified from these mice 42 days after infection and transferred to OVA-sensitized BALB/c mice, which were then challenged with OVA to induce AHR. (F) Left: After OVA challenge, AHR was measured as described in $\mathbf{D}$. Right: Cells in BAL were assessed. ${ }^{* \star *} P<0.001$ compared with the WT-OVA group. Data are representative of 2 independent experiments. 
with the expansion of allergen-specific Foxp $3^{+}$Treg cells, suggesting that the suppressive effect was mediated by Foxp $3^{+}$Treg cells. Moreover the protective effect of H3N1 infection could be replicated by treating suckling mice with NKT cell-activating glycolipids from $H$. pylori or with $\alpha$-C-GalCer. These studies are particularly important not only because they characterize an NKT cell population that suppresses AHR, but also because they provide a plausible mechanism for the hygiene hypothesis and for epidemiological studies indicating that infection with respiratory viruses (9) and H. pylori $(2,3)$ protect against the development of asthma.

NKT cells comprise a small subset of T lymphocytes that share characteristics with NK cells and conventional T cells, with potent functions in modulating immunity that have only recently become appreciated (33). NKT cells express a relatively unique transcription factor, PLZF, specific for NKT cells (34) and other innate or activated T cells (35), and an invariant TCR, Vo14J $\alpha 18$ in mice and $\mathrm{V} \alpha 24$ in humans, and are restricted by the MHC class I-like molecule, CD1d. The conservation of this invariant TCR across many mammalian species suggests that it is a pattern recognition receptor, and that NKT cells play an important role in innate immunity. Activation of NKT cells through this invariant TCR results in the rapid production of large amounts of cytokines, including IL-4 and IFN- $\gamma$, particularly from mature NKT cells found in adult mice and humans. In contrast, NKT cells in neonates or in cord blood are immature, and produce only small amounts of cytokines $(36,37)$. Nevertheless, the ability of mature NKT cells to rapidly produce very large quantities of cytokines endows that NKT cell with the capacity to play very important regulatory roles in autoimmunity, cancer, asthma, and infectious diseases (38).

NKT cells participate in immune responses to a growing list of infectious microorganisms, driven either by direct TCR recognition of specific glycolipids expressed by microorganisms, as in the case of Borrelia burgdorferI (39) and Sphingomonas paucimobilis $(32,40)$, or by indirect responses to cytokines released by activated DCs, as in the case of Salmonella typhimurium (41), E. coli, Staphylococcus aureus, Listeria monocytogenes (42), and Mycobacteria tuberculosis $(43,44)$. During influenza A infection in adult mice, NKT cells abolished the suppressive activity of influenza A-induced myeloidderived suppressor cells, thereby enhancing survival (18). Our current studies also suggest that NKT cells may respond during infection with influenza A, and to glycolipids (PI57) produced by $H$. pylori, resulting in inhibitory effects on immunity, though primarily in young mice. The capacity of $H$. pylori glycolipids to activate a regulatory NKT cell subset (but only in young mice) may also explain the protective effects of $H$. pylori infection in neonatal but not older mice against gastritis and malignant metaplasia (45) as well as the observation that only WT, and not cholesterol- $\alpha$-glucosyltransferase-deficient, $H$. pylori can infect the gastric mucosa of mice (28), given that cholesterol- $\alpha$-glucosyltransferase is required for synthesis of PI57 (46). Finally, we would like to point out that the structure and function of PI57 is unique, since it includes a cholesterol-containing tail distinct from previously described NKT cell ligands, and since it represents the first demonstration of cholesterol as a target for TCR recognition.

NKT cells thus react to a diverse group of pathogens by functioning as an innate immune cell that can sense and rapidly respond to the presence of infectious agents. The capacity to respond to such pathogens, however, may be limited in neonates and young children due to limited numbers and to the immaturity of NKT cells $(36,37)$. On the other hand, the immaturity of NKT cells in young children may provide an opportunity for infection and therapeutic intervention to influence the subset composition of NKT cells, thereby preventing the development of asthma and allergy.

In asthma, NKT cells have been suggested to play a very important pathogenic role $(20,47)$. This idea has become controversial, since some patients, particularly those with mild or well-controlled asthma, have few detectable pulmonary NKT cells, although patients with severe or poorly controlled asthma have a significant increase in pulmonary NKT cells $(19,48,49)$. Nevertheless, in many distinct mouse models of asthma, the presence of specific NKT cell subsets was required for the development of AHR. For example, $\mathrm{CD}^{+} \mathrm{IL}-17 \mathrm{RB}^{+} \mathrm{NKT}$ cells are required in allergen-induced AHR (19, 20, 50, 51); in ozone-induced AHR, an NK1.1- IL-17-producing subset is required (21); and in Sendai virus-induced AHR, a $\mathrm{CD} 4^{+} \mathrm{NKT}$ cell population that interacts with alternatively activated alveolar macrophages is required (22). While previous studies have suggested that some (DN) NKT cells could not induce AHR (50), we now show for the first time that a population of NKT cells, enriched for a DN, T-bet-dependent, and IFN- $\gamma$-producing subset, has a potent regulatory role, suppressing the development of AHR. Although previous studies have suggested an inhibitory role for NKT cells in asthma, since adoptive transfer of NKT cells acutely activated with $\alpha$-GalCer (1 hour prior to transfer) inhibit the development of experimental asthma in a C57BL/6 mouse model (52), we believe that our current studies are quite distinct. We showed that $\mathrm{H} 3 \mathrm{~N} 1$ infection in suckling mice expanded a population of NKT cells that, when examined 42 days after infection, specifically suppressed allergen-induced AHR without the need for acute activation with exogenous glycolipids.

While H3N1 infection affects many different cell types, the fact that the protective effect of $\mathrm{H} 3 \mathrm{~N} 1$ infection could be transferred with purified NKT cells, and the fact that the protective effect could be replicated by treatment of suckling mice with $\alpha$-C-GalCer or a glycolipid from $H$. pylori (PI57) that specifically activated NKT cells in a CD1d-restricted fashion, strongly suggests that the protective effect of $\mathrm{H} 3 \mathrm{~N} 1$ infection in young mice was primarily mediated by a subset of NKT cells. The NKT cell subset activated by PI57 in suckling mice appeared to be a subset of invariant NKT cells, since DN NKT cells in suckling mice expanded after treatment with PI57, and since CD1d tetramers loaded with PI57 could stain NKT cells. The precise mechanism by which the DN NKT cells suppressed AHR is not clear, but may involve the preferential production of IFN- $\gamma$ but not IL-4, since DN NKT cells from H3N1-infected suckling Tbet ${ }^{-}$mice failed to inhibit AHR. A role for IFN- $\gamma$ is also supported by our observation that treatment of suckling mice with $\alpha$-C-GalCer, which preferentially induces IFN- $\gamma$ (26), also prevented the development of OVA-induced AHR 42 days later, whereas treatment with $\alpha$-GalCer or with Sphingomonas glycolipid (PBS30) did not.

The "regulatory" NKT cells mediating the inhibitory effect of H3N1 and of PI57 and $\alpha$-C-GalCer may be similar to previously described DN NKT cells that protected against the development of type I diabetes in humans and in mice $(53,54)$, to IFN- $\gamma$-producing NKT cells that were required for allograft tolerance (55), or to IL-4-producing NKT cells that induced Treg cells in the prevention of graft versus host disease (56-58). In our experiments, increased numbers of both natural and adaptive OVA-specific Treg cells were associated with the regulatory NKT cells and were blocked by treatment with anti-CD25 mAb (Figure 4, F and G). Moreover, we believe that our studies are the first to demonstrate the existence of a 

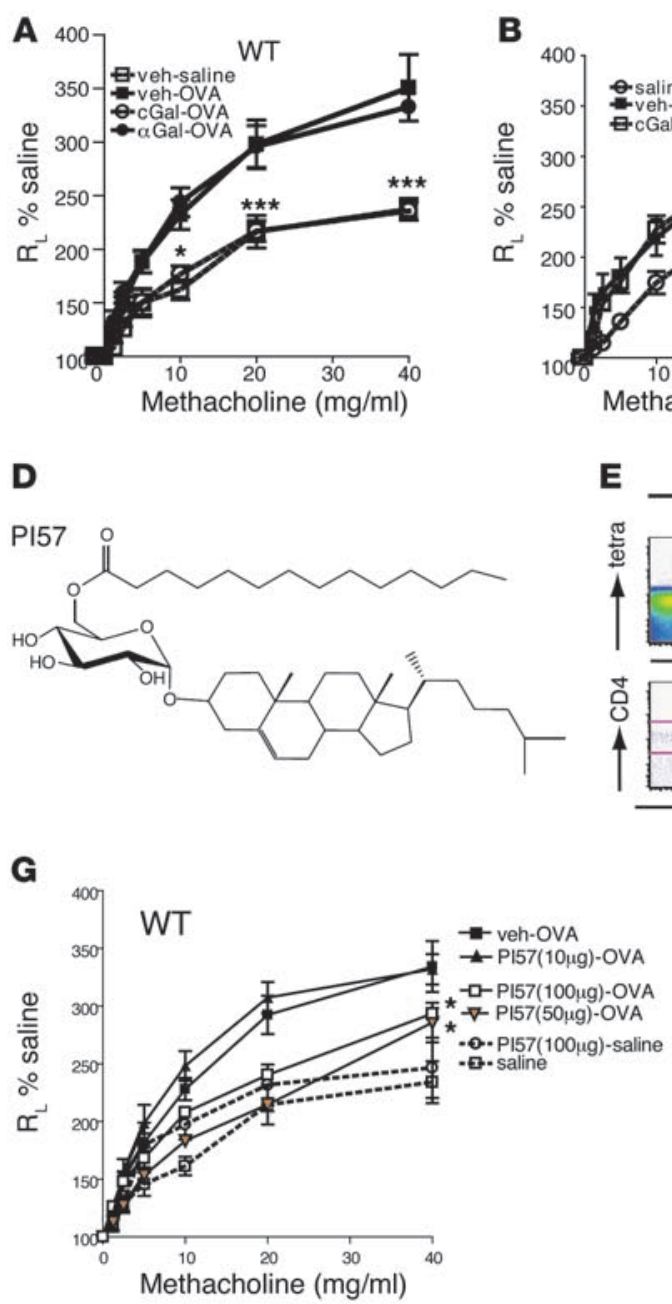
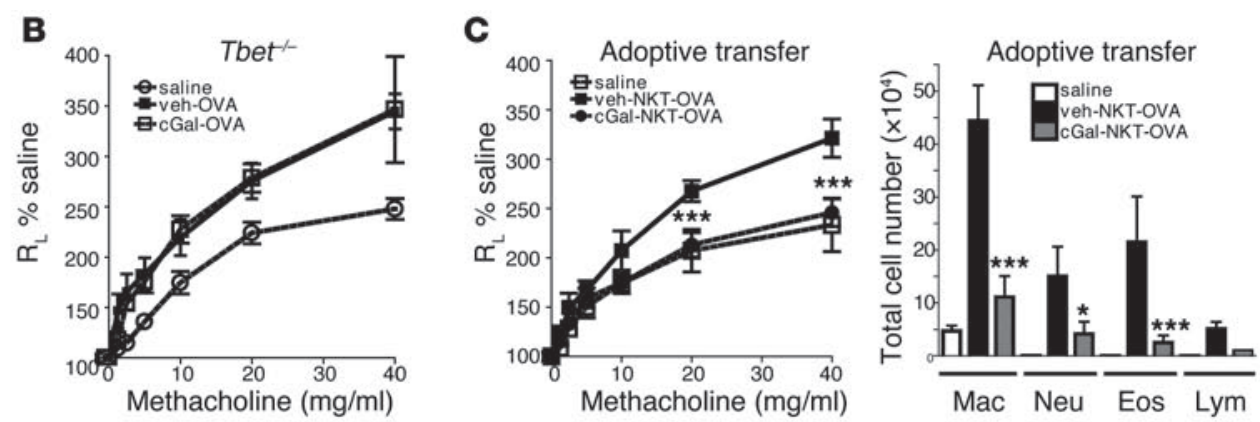

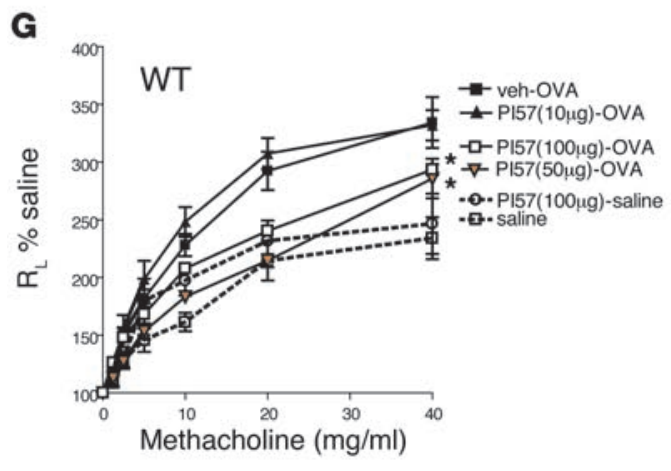

I

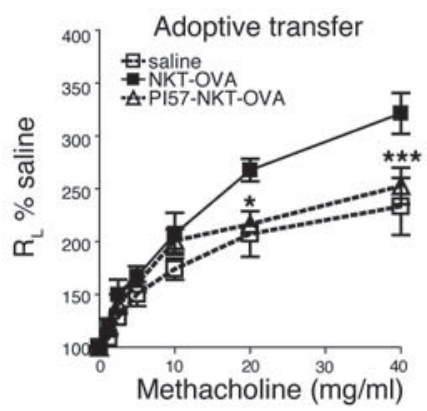

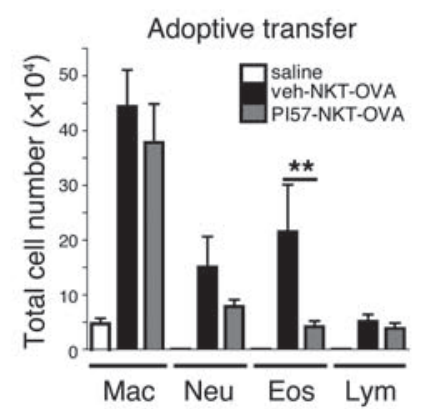
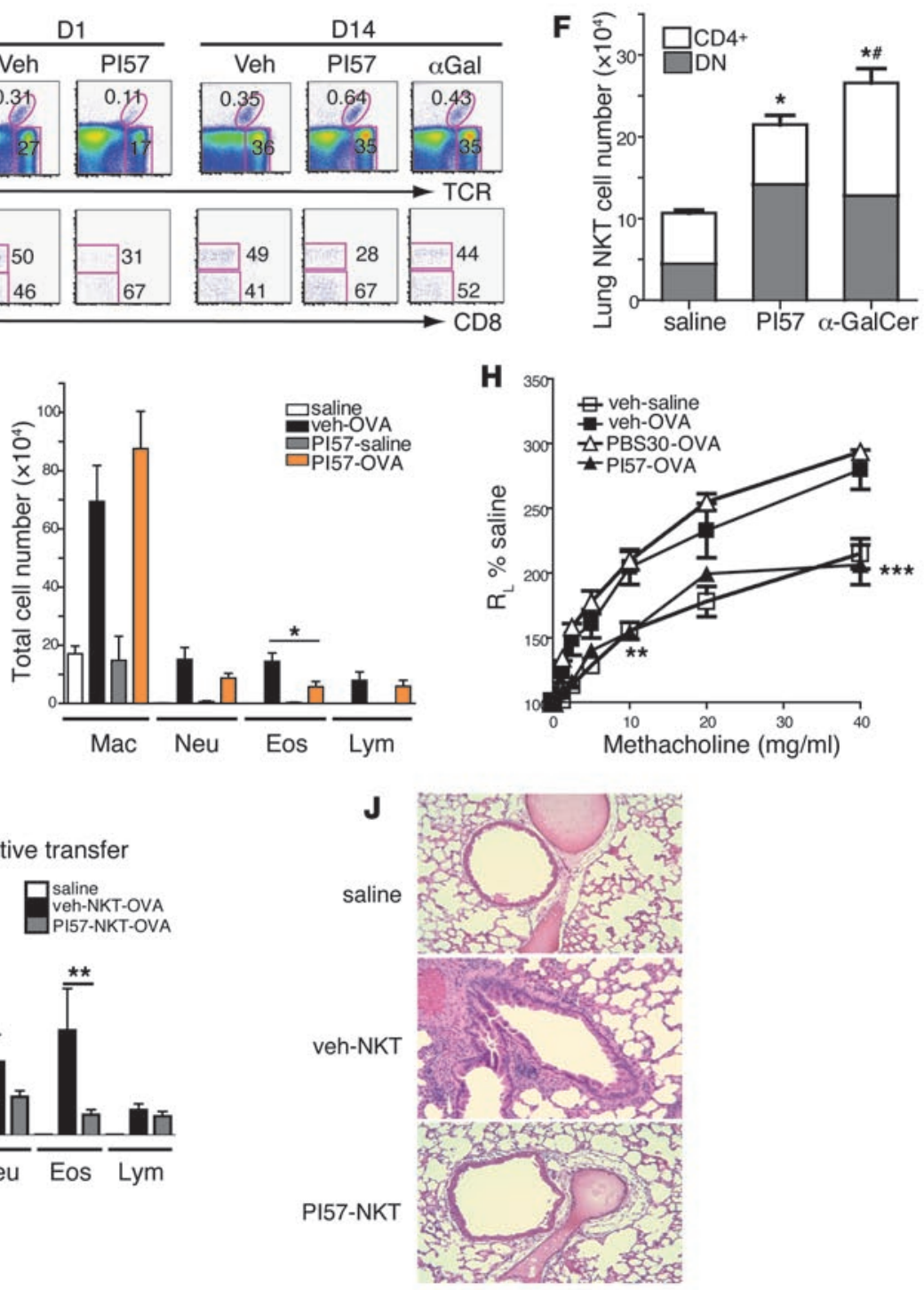

Figure 6

Induction of protection with $\alpha-C$-GalCer and a glycolipid from H. pylori. (A) Two-week-old BALB/c mice $(n=6-8 /$ group $)$ or (B) Tbet ${ }^{/-}$mice $(n=4-6$ per group) received $5 \mu \mathrm{g} \alpha$-GalCer (cGal), $2 \mu \mathrm{g} \alpha$-GalCer, or vehicle. After OVA sensitization and challenge, AHR was measured on day 44 . (C) Donor mice were treated with $\alpha$-C-GalCer $(5 \mu \mathrm{g})$ or vehicle i.p. NKT cells served as donors, as in Figure $4 \mathrm{~A}(n=4$ per group). Lung resistance (left) and cell counts in BAL (right) were assessed. (D) Structure of PI57. (E) Mice received PI57 (50 $\mu \mathrm{g}), \alpha$-GalCer (2 $\mu \mathrm{g})$, or vehicle i.p., and lungs were examined 1 or 14 days later for CD4 and CD8 expression. (F) Absolute numbers of CD4+ NKT and DN NKT subsets from $\mathbf{E}$ were assessed. (G) BALB/c mice ( $n=5-8$ /group) received PI57 or vehicle i.p. Lung resistance (left) and BAL cells (right) were assessed. (H) BALB/c mice treated with PI57 (50 $\mu$ g), PBS30 (Sphingomonas glycolipid) $(50 \mu \mathrm{g})$, or vehicle i.p. were assessed for AHR as in G. (I) Donor mice were treated with PI57 (50 $\mu \mathrm{g})$ or vehicle i.p. NKT cells served as donors as in Figure 4A. Lung resistance (left) and BAL cells (right) were assessed $(n=4$ per group). (J) Representative lung sections from I stained with $\mathrm{H} \& \mathrm{E}$ (original magnification, $\times 10$ ). Data represent $2-3$ independent experiments. ${ }^{*} P<0.05,{ }^{\sharp} P<0.05$, ${ }^{\star * \star} P<0.001$ versus vehicle-OVA (C, G, and I), DN NKT saline (F), and CD4+ NKT saline (F). 
A

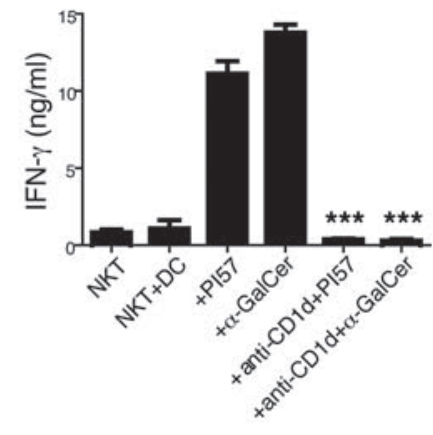

C
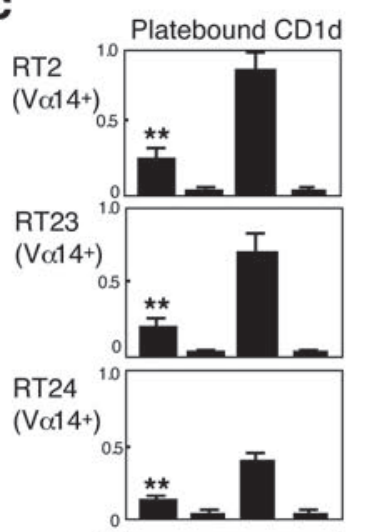

RT8

(Vo14-)

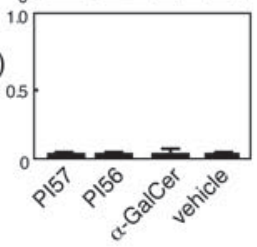

B
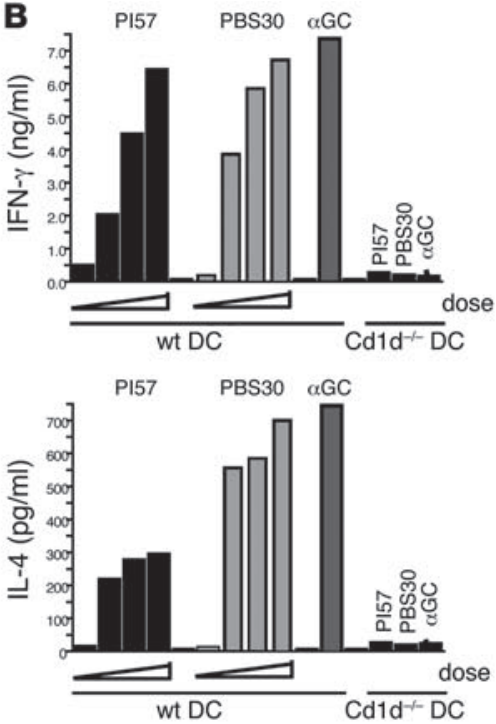

D

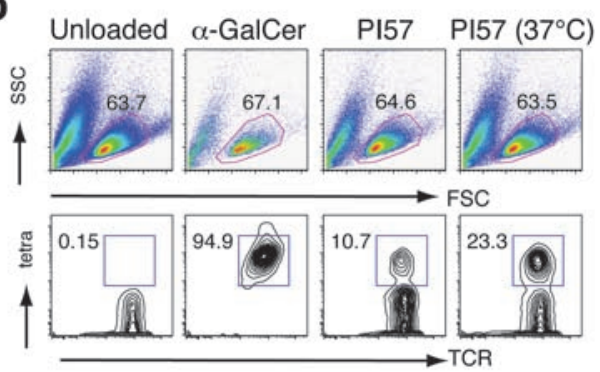

E

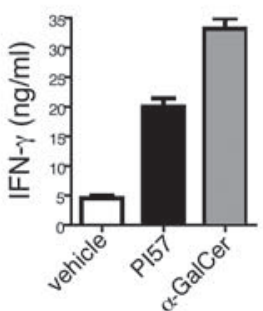

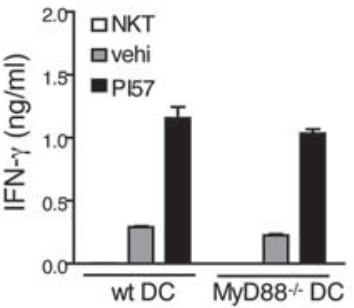
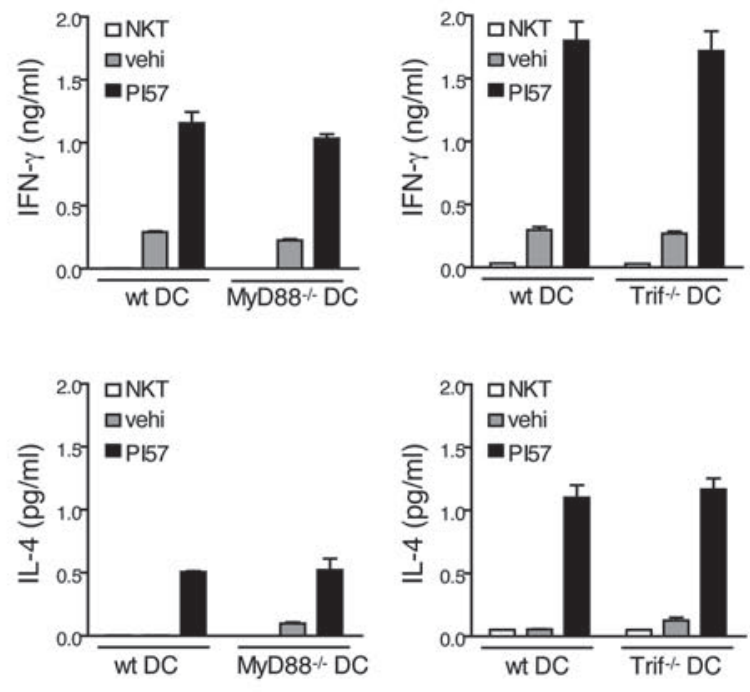

F
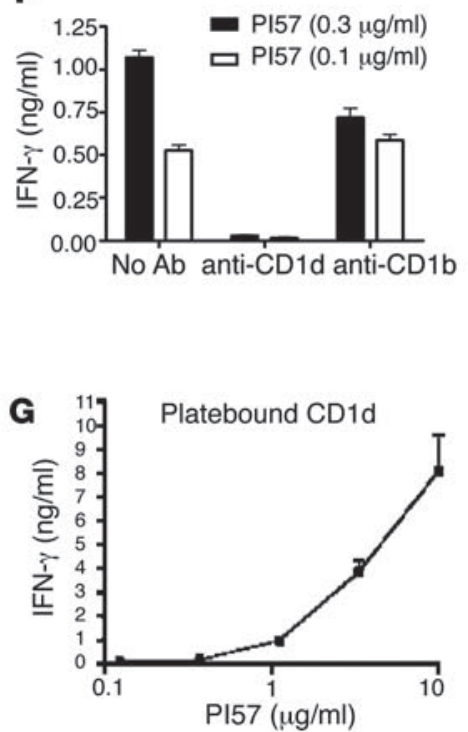

Figure 7

PI57 directly activates NKT cells. (A) NKT cell lines were cocultured with BM-derived DCs (BMDCs) and $\alpha$-GalCer (100 ng/ml), PI57 (10 $\mu \mathrm{g} / \mathrm{ml})$, or vehicle for 48 hours, with or without pre-incubation with anti-CD1d $(10 \mu \mathrm{g} / \mathrm{ml})$. IFN- $\gamma$ was measured by ELISA. (B) Murine NKT cell lines were cocultured as in A with BMDCs from WT, Cd1 $1 \mathrm{~d}^{-1-}, \mathrm{Myd8}^{-/-}$, or Trif ${ }^{-1}$ mice. Cells were treated with $\alpha-\mathrm{GalCer}(100 \mathrm{ng} / \mathrm{ml}), \mathrm{PI} 57$ (2.5, 5 , or $10 \mu \mathrm{g} / \mathrm{ml})$, PBS30 $(1,2.5$, or $5 \mu \mathrm{g} / \mathrm{ml})$, or vehicle for 48 hours. IFN- $\gamma$ and IL-4 were measured by ELISA. (C) IL-2 production from hybridomas derived from invariant $\mathrm{V} \alpha 14$ NKT cells (RT2, RT23, and RT24) and an irrelevant V $\beta 8^{+}$T cell (RT8; control) (see Supplemental Methods). (D) Mouse NKT cell lines were stained with PE-labeled CD1d tetramers of PI57 or $\alpha$-GalCer at $4^{\circ} \mathrm{C}$ for 45 minutes or $37^{\circ} \mathrm{C}$ for 25 minutes, and with anti-TCR $\beta$-APC antibody. Top: Lymphocytes were gated in the FSC/SSC window. Bottom: Percentage of CD1d tetramer+ cells. (E) IFN- $\gamma$ and IL-4 production from human NKT cell lines by treatment with $\alpha$-GalCer $(100 \mathrm{ng} / \mathrm{ml}), \mathrm{PI} 57(10 \mu \mathrm{g} / \mathrm{ml})$, or vehicle for 48 hours in vitro (see Supplemental Methods). (F) IFN- $\gamma$ production from CD1d-transfected NKT cell clone BM2a.3 in presence of PI57 and blocking mAb against human CD1d or CD1b (see Supplemental Methods). (G) CD1d Fc-coated Maxisorp plates were loaded with lipid and cultured with $5 \times 10^{4}$ NKT cells. IFN- $\gamma$ was analyzed by ELISA after 24 hours. Data represent 3 or 5 independent experiments.

subpopulation of NKT cells that can suppress the effects of other subpopulations of NKT cells that enhance the development of experimental asthma. These results suggest that a balance exists between NKT cells that induce, and those that protect against, AHR, and that stimulation with $\mathrm{H} 3 \mathrm{~N} 1, \alpha-\mathrm{C}-\mathrm{GalCer}$, or $H$. pylori glycolipids, but not a Sphingomonas glycolipid or $\alpha$-GalCer, may selectively expand this regulatory NKT cell population in young mice. The inability of
$\alpha$-GalCer to protect may be due to the fact that it nonselectively stimulates all invariant NKT cells or because it may anergize NKT cells, including suppressive populations. Nevertheless, these data support the idea that under normal, pathogen-free conditions, $\mathrm{CD} 4^{+} \mathrm{NKT}$ cells that induce AHR predominate, but that in very young mice, exposure to Th1-skewing reagents that can alter the composition of NKT cell subpopulations may change subsequent lung immunity. 
Therefore, it appears that the balance between $\mathrm{CD} 4^{+}$versus regulatory (presumably DN) NKT cells is determined or imprinted early in life but might be influenced by exposure to specific types of infections, particularly those that can affect NKT cells. In our studies, $\mathrm{H} 3 \mathrm{~N} 1$ infection in 2-week-old pups activated the immature NKT cells and preferentially expanded a DN NKT cell subset. In addition, our studies suggest that $\alpha$-C-GalCer and glycolipids from $H$. pylori can profoundly affect this NKT cell subpopulation, which may explain epidemiological studies showing an association of $H$. pylori infection with protection against asthma $(2,3)$. Although these studies were performed in mice, which mature from neonates to adults in only 35 days versus many years in humans, taken together, our results suggest that infection with certain microorganisms can prevent the subsequent development of asthma and allergy by expanding the relative proportion of a specific subset of NKT cells, thus providing an immunological mechanism for the hygiene hypothesis. Finally, these results predict that treatment of children with compounds such as $\alpha$-C-GalCer and others derived from microorganisms (e.g., H. pylori) might expand this regulatory NKT cell subset and be effective in preventing the development of asthma.

\section{Methods}

Mice. WT BALB/c ByJ and Tbet $/$ (C.129S6-Tbx21tm1Glm/J) mice were purchased from The Jackson Laboratory. J $\alpha 18^{-/-}$mice were gifts from M. Taniguchi and T. Nakayama (Chiba University, Chiba, Japan). $T l r 7^{-1}$ mice were generated by Shizuo Akira, and the V $\alpha 14 \mathrm{Tg}$ mice were provided by Albert Bendelac (University of Chicago, Chicago, Illinois, USA). These strains were backcrossed to $\mathrm{BALB} / \mathrm{c}$ for more than 10 generations. DO11.10 X Rag ${ }^{-/}$mice were provided by Abul Abbas (UCSF, San Francisco, California, USA). For studies in suckling mice, BALB/c, $T l r 7^{-1-}$, and $\mathrm{Tbet}^{-1-}$ mice were bred, and the offspring were infected at 2 weeks of age, then weaned at 3 weeks. The Animal Care and Use Committee at Children's Hospital Boston approved all animal protocols.

Influenza A infection. Two-week-old pups (suckling mice) or 8-week-old adult mice were anesthetized with $3 \%$ isoflurane and inoculated intranasally (i.n.) with influenza A virus (strain Mem/71 [H3N1]) in $20 \mu \mathrm{l} \mathrm{PBS} \mathrm{for}$ suckling mice or $50 \mu \mathrm{l}$ PBS for adult mice. The virus is a reassortant influenza virus strain carrying the hemagglutinin of A/Memphis/1/71 (H3) and the neuraminidase of A/Bellamy/42 (N1). The virus was grown and harvested from 10-day embryonated chicken eggs as previously described (59). The dose of virus used $\left(1.2 \times 10^{4} \mathrm{PFU} /\right.$ mouse $)$ causes nonlethal pneumonia of both suckling and adult mice, with complete virus clearance around day 7 after infection. Control (mock-infected) mice were treated with i.n. allantoic fluid (AF) diluted 1:500 in PBS.

Reagents. $\alpha$-GalCer and PBS30 (31) were synthesized by P.B. Savage (Brigham Young University, Provo, Utah, USA). H. pylori glycolipids were extracted and purified as described in the Supplemental Methods. The H. pylori glycolipid PI57 (cholesteryl 6-O-tetradecanoyl- $\alpha$-D-glucopyranoside) was synthesized based on ${ }^{1} \mathrm{H},{ }^{13} \mathrm{C}$ NMR spectrometry, TLC analysis, ES-mass spectrometry of lipids from $H$. pylori SS1 and human H. pylori S strains (Supplemental Figure 4 and Supplemental Methods), and data reported for purified $H$. pylori glycolipids (30). An analog of $\alpha$-C-GalCer, called "GCK151", which has activity with mouse and human NKT cells (27), was synthesized by Richard W. Franck (Hunter College of CUNY).

PI57-loaded CD1d tetramers. To generate PI57-loaded mCD1d monomers, a 10 -fold molar excess of PI57 in DMSO at $2 \mathrm{mg} / \mathrm{ml}$ was incubated with biotinylated-mCD1d (from the NIH Tetramer facility) in 2 mM CHAPS and $20 \mathrm{mM}$ Tris $\mathrm{pH} 7.0$ overnight at room temperature. The mCD1d monomers were tetramerized by adding SA-PE (S868; Invitrogen) to the lipid-loaded monomers as previously described (60).
Induction of AHR and measurement of airway responsiveness in the OVA model. To induce AHR, BALB/c mice were sensitized with $100 \mu \mathrm{g}$ of OVA (SigmaAldrich) in alum administered i.p (on day 0). After sensitization, mice were exposed to i.n. antigen (50 $\mu \mathrm{g}$ OVA/day) or normal saline for 1 day (day 7; single-dose challenge protocol) or for 3 consecutive days (days 7-9). AHR was assessed on the day after last OVA challenge. Control mice received i.p. injection of PBS and i.n. administrations of normal saline.

Collection and analysis of bronchoalveolar lavage. Immediately after the AHR measurement, mice were euthanized and the lungs were lavaged twice with $0.5 \mathrm{ml}$ of PBS, and the fluid was pooled. Cells in bronchoalveolar lavage (BAL) were counted and analyzed as previously described (20). The relative number of different types of leukocytes was determined from slide preparations of BAL stained with Diff-Quik solution (Dade Behring).

Adoptive transfer of NKT cells. NKT cells were purified from splenocytes of WT BALB/c, influenza virus-infected BALB/c, influenza virus-infected $T l r 7^{-/}$, influenza virus-infected Tbet ${ }^{-/}$, V $\alpha 14$ TCR transgenic mice, PI57-treated BALB/c, and $\alpha$-GalCer-treated BALB/c mice using magnetic cell sorting (MACS), as previously described (20). Splenic NKT cells were labeled with PE-conjugated CD1d tetramer, followed by anti-PE microbeads (Miltenyi Biotec) and then sorted with AutoMACS according to the manufacturer's instruction. Purity of NKT cells was approximately 93\% (Supplemental Figure 2A), and there was no detectable Treg cell contamination (Supplemental Figure 2B). Purified NKT cells were adoptively transferred into immunized recipient mice by intravenous injection $\left(10^{6}\right.$ for $J \alpha 18^{-1-} ; 5 \times 10^{5}$ for BALB/c) 1 hour before the first challenge of OVA (day 7). For the OVA-specific Treg cell experiment, $5 \times 10^{4}$ DO11.10 CD4 ${ }^{+} \mathrm{T}$ cells (from DO11.10 $\times \mathrm{Rag}^{-1-}$ mice) were adoptively transferred into recipient mice 5 hours before sensitization with OVA/ alum (day 0). The recipients later received NKT cells 1 hour before the first challenge of OVA (day 7).

ELISA. Mouse or human IL-4 and IFN- $\gamma$ levels were measured by ELISA, as previously described (20). Mean values of triplicate cultures were shown. Data are representative of 2 or 3 independent experiments.

Statistics. Differences between groups with parametric distributions were analyzed using the Student's 2-tailed $t$ test. Otherwise, the Mann-Whitney $U$ test was used. Data represent mean \pm SEM. $P$ values of 0.05 or less were considered statistically significant.

\section{Acknowledgments}

These studies were supported by grants from the NIH RO1 AI68085, R01 HL62348, R01 AI026322, and RC1 HL069507, by an award from the Bunning Food Allergy Project, and by grant 20570146 from the Ministry of Education, Culture, Sports, Science, and Technology of Japan. The authors thank Dirk Zajonc for help in loading CD1d molecules, and the NIH NIAID Tetramer Facility for providing CD1d monomers and PBS57-CD1d tetramers.

Received for publication August 20, 2010, and accepted in revised form October 20, 2010.

Address correspondence to: Dale T. Umetsu, Karp Labs, Rm 10127, One Blackfan Circle, Boston, Massachusetts 02115, USA. Phone: 617.919.2439; Fax: 617.730.0384; E-mail: dale.umetsu@childrens. harvard.edu. Or to: Michio Shimamura, Tsukuba Research Center for Interdisciplinary Materials Science, University of Tsukuba, 1-1-1 Tennodai, Ibaraki 305-8571, Japan. Phone: 81.29.853.4527; Fax: 81.29.853.4507; E-mail: michio@chem.tsukuba.ac.jp. Or to: Petr Illarionov, University of Birmingham School of Biosciences, Edgbaston B15 2TT, Birmingham, United Kingdom. Phone: 44.121.4158123; Fax: 44.121.4145925; E-mail: illar@yahoo.com. 
1. Strachan DP. Hay fever, hygiene, and household size. BMJ. 1989;299(6710):1259-1260.

2. Matricardi P, et al. Exposure to foodborne and orofecal microbes versus airborne viruses in relation to atopy and allergic asthma: epidemiological study. BMJ. 2000;320(7232):412-417.

3. Reibman J, et al. Asthma is inversely associated with Helicobacter pylori status in an urban population. PLoS One. 2008;3(12):e4060.

4. Braun-Fahrlander C, et al. Environmental exposure to endotoxin and its relation to asthma in schoolage children. N Engl J Med. 2002;347(12):869-877.

5. Conrad ML, et al. Maternal TLR signaling is required for prenatal asthma protection by the nonpathogenic microbe Acinetobacter lwoffii F78. J Exp Med. 2009;206(13):2869-2877.

6. Matricardi PM, et al. Cross sectional retrospective study of prevalence of atopy among Italian military students with antibodies against hepatitis A virus. BMJ. 1997;314(7086):999-1003.

7. Matricardi PM, Rosmini F, Panetta V, Ferrigno L, Bonini S. Hay fever and asthma in relation to markers of infection in the United States. J Allergy Clin Immunol. 2002;110(3):381-387.

8. Jackson DJ, et al. Wheezing rhinovirus illnesses in early life predict asthma development in high-risk children. Am J Respir Crit Care Med. 2008;178(7):667-672.

9. Martinez FD, et al. Asthma and wheezing in the first six years of life. New Engl J Med. 1995;332(3):133-138.

10. von Mutius E, Martinez FD, Fritzsch C, Nicolai T, Roell G, Thiemann HH. Prevalence of asthma and atopy in two areas of West and East Germany. Am J Respir Crit Care Med. 1994;149(2 pt 1):358-364.

11. Tsitoura DC, Kim S, Dabbagh K, Berry G, Lewis DB, Umetsu DT. Respiratory infection with influenza A virus interferes with the induction of tolerance to aeroallergens. J Immunol. 2000;165(6):3484-3491.

12. Dahl M, Dabbagh K, Liggitt D, Kim S, Lewis D Viral-induced $\mathrm{T}$ helper type 1 responses enhance allergic disease by effects on lung dendritic cells. Nat Immunol. 2004;5(3):337-343.

13. Marsland B, Harris N, Camberis M, Kopf M, Hook S, Le Gros G. Bystander suppression of allergic airway inflammation by lung resident memory CD $8+T$ cells. Proc Natl Acad Sci US A. 2004;101(16):6116-6121.

14. Wohlleben $G$, et al. Influenza A virus infection inhibits the efficient recruitment of Th2 cells into the airways and the development of airway eosinophilia. J Immunol. 2003;170(9):4601-4611.

15. Glezen WP, Greenberg SB, Atmar RL, Piedra PA, Couch RB. Impact of respiratory virus infections on persons with chronic underlying conditions. JAMA. 2000;283(4):499-505.

16. Miller EK, et al. Influenza burden for children with asthma. Pediatrics. 2008;121(1):1-8.

17. Jain S, et al. Hospitalized patients with 2009 H1N1 influenza in the United States, April-June 2009. NEngl J Med. 2009;361(20):1935-1944.

18. De Santo C, et al. Invariant NKT cells reduce the immunosuppressive activity of influenza A virusinduced myeloid-derived suppressor cells in mice and humans. J Clin Invest. 2008;118(12):4036-4048.

19. Matangkasombut P, Pichavant M, Dekruyff RH, Umetsu DT. Natural killer T cells and the regulation of asthma. Mucosal Immunol. 2009;2(5):383-392.

20. Akbari O, et al. Essential role of NKT cells producing IL-4 and IL-13 in the development of allergeninduced airway hyperreactivity. Nature Medicine. 2003;9(5):582-588

21. Pichavant $M$, et al. Ozone exposure in a mouse model induces airway hyperreactivity that requires the presence of natural killer T cells and IL-17. J Exp
Med. 2008;205(2):385-393.

22. Kim EY, et al. Persistent activation of an innate immune response translates respiratory viral infection into chronic lung disease. Nat Med. 2008; 14(6):633-640.

23. Townsend MJ, et al. T-bet regulates the terminal maturation and homeostasis of NK and Valpha14i NKT cells. Immunity. 2004;20(4):477-494.

24. Kim HY, et al. The development of airway hyperreactivity in T-bet-deficient mice requires CD1d-restricted NKT cells. J Immunol. 2009;182(5):3252-3261.

25. Schmieg J, Yang G, Franck RW, Tsuji M. Superior protection against malaria and melanoma metastases by a C-glycoside analogue of the natural killer $\mathrm{T}$ cell ligand alpha-Galactosylceramide. J Exp Med. 2003;198(11):1631-1641

26. Fujii S, et al. Glycolipid alpha-C-galactosylceramide is a distinct inducer of dendritic cell function during innate and adaptive immune responses of mice. Proc Natl Acad Sci U S A. 2006;103(30):11252-11257.

27. Li X, Chen G, Garcia-Navarro R, Franck RW, Tsuji $\mathrm{M}$. Identification of C-glycoside analogues that display a potent biological activity against murine and human invariant natural killer T cells. Immunology. 2009;127(2):216-225

28. Wunder C, et al. Cholesterol glucosylation promotes immune evasion by Helicobacter pylori. Nat Med. 2006;12(9):1030-1038.

29. Linz B, et al. An African origin for the intimate association between humans and Helicobacter pylori. Nature. 2007;445(7130):915-918.

30. Hirai Y, Haque M, Yoshida T, Yokota K, Yasuda T, Oguma K. Unique cholesteryl glucosides in Helicobacter pylori: composition and structural analysis. J Bacteriol. 1995;177(18):5327-5333.

31. Mattner J, et al. Exogenous and endogenous glycolipid antigens activate NKT cells during microbial infections. Nature. 2005;434(7032):525-529.

32. Kinjo Y, et al. Recognition of bacterial glycosphingolipids by natural killer T cells. Nature. 2005;434(7032):520-525.

33. Bendelac A, Savage PB, Teyton L. The biology of NKT cells. Annu Rev Immunol. 2007;25:297-336.

34. Savage AK, et al. The transcription factor PLZF directs the effector program of the NKT cell lineage. Immunity. 2008;29(3):391-403.

35. Kreslavsky T, et al. TCR-inducible PLZF transcription factor required for innate phenotype of a subset of gammadelta $T$ cells with restricted TCR diversity. Proc Natl Acad Sci U S A. 2009; 106(30):12453-12458.

36. Kadowaki N, et al. Distinct cytokine profiles of neonatal natural killer $\mathrm{T}$ cells after expansion with subsets of dendritic cells. J Exp Med. 2001;193(10):1221-1226.

37. D'Andrea A, et al. Neonatal invariant Valpha24+ NKT lymphocytes are activated memory cells. Eur J Immunol. 2000;30(6):1544-1550.

38. Kronenberg M. Toward an understanding of NKT cell biology: progress and paradoxes. Annu Rev Immunol. 2005;23:877-900.

39. Kinjo Y, et al. Natural killer $\mathrm{T}$ cells recognize diacylglycerol antigens from pathogenic bacteria. Nat Immunol. 2006;7(9):978-986.

40. Mattner J, et al. Exogenous and endogenous glycolipid antigens activate NKT cells during microbial infections. Nature. 2005;434(7032):525-529.

41. Brigl M, Bry L, Kent SC, Gumperz JE, Brenner MB. Mechanism of CD1d-restricted natural killer T cell activation during microbial infection. Nat Immunol. 2003;4(12):1230-1237.

42. Kim S, Lalani S, Parekh VV, Vincent TL, Wu L, Van
Kaer L. Impact of bacteria on the phenotype, functions, and therapeutic activities of invariant NKT cells in mice. J Clin Invest. 2008;118(6):2301-2315.

43. Fischer K, et al. Mycobacterial phosphatidylinositol mannoside is a natural antigen for CD1drestricted T cells. Proc Natl Acad Sci U S A. 2004; 101(29):10685-10690.

44. Sada-Ovalle I, Chiba A, Gonzales A, Brenner MB, Behar SM. Innate invariant NKT cells recognize Mycobacterium tuberculosis-infected macrophages, produce interferon-gamma, and kill intracellular bacteria. PLoS Pathog. 2008;4(12):e1000239.

45. Arnold I, et al. Tolerance rather than immunity protects from Helicobacter pylori -induced gastric preneoplasia [published online ahead of print June 23, 2010]. Gastroenterology. doi:10.1053/ j.gastro.2010.06.047.

46. Lebrun AH, et al. Cloning of a cholesterol-alphaglucosyltransferase from Helicobacter pylori. J Biol Chem. 2006;281(38):27765-27772.

47. Lisbonne $\mathrm{M}$, et al. Cutting edge: invariant $\mathrm{V}$ alpha 14 NKT cells are required for allergeninduced airway inflammation and hyperreactivity in an experimental asthma model. J Immunol. 2003;171(4):1637-1641.

48. Akbari O, et al. CD4+ invariant T-cell-receptor+ natural killer T cells in bronchial asthma. NEnglJ Med. 2006;354(11):1117-1129.

49. Vijayanand $P$, et al. Invariant natural killer T cells in asthma and chronic obstructive pulmonary disease. NEngl J Med. 2007;356(14):1410-1422.

50. Stock P, Lombardi V, Kohlrautz V, Akbari O. Induction of airway hyperreactivity by IL-25 is dependent on a subset of invariant NKT cells expressing IL17RB. JImmunol. 2009;182(8):5116-5122.

51. Terashima A, et al. A novel subset of mouse NKT cells bearing the IL-17 receptor B responds to IL25 and contributes to airway hyperreactivity. J Exp Med. 2008;205(12):2727-2733.

52. Hachem $\mathrm{P}$, et al. Alpha-galactosylceramide-induced iNKT cells suppress experimental allergic asthma in sensitized mice: role of IFN-gamma. Eur J Immunol. 2005;35(10):2793-2802.

53. Wilson SB, et al. Extreme Th1 bias of invariant Valpha24JalphaQ T cells in type 1 diabetes. Nature. 1998;391(6663):177-181.

54. Diana J, et al. NKT cell-plasmacytoid dendritic cell cooperation via OX40 controls viral infection in a tissue-specific manner. Immunity. 2009;30(2):289-299.

55 . Seino KI, et al. Requirement for natural killer $\mathrm{T}$ (NKT) cells in the induction of allograft tolerance. Proc Natl Acad Sci U S A. 2001;98(5):2577-2581.

56. Zeng D, et al. Bone marrow NK1.1(-) and NK1.1(+) $\mathrm{T}$ cells reciprocally regulate acute graft versus host disease. J Exp Med. 1999;189(7):1073-1081.

57. Lowsky R, et al. Protective conditioning for acute graft-versus-host disease. N Engl J Med. 2005; 353(13):1321-1331.

58. Pillai AB, George TI, Dutt S, Strober S. Host natural killer $T$ cells induce an interleukin-4-dependent expansion of donor CD4+CD25+Foxp3+ T regulatory cells that protects against graft-versus-host disease. Blood. 2009;113(18):4458-4467.

59. Baumgarth N, Brown L, Jackson D, Kelso A. Novel features of the respiratory tract T-cell response to influenza virus infection: lung $T$ cells increase expression of gamma interferon mRNA in vivo and maintain high levels of mRNA expression for interleukin5 (IL-5) and IL-10. J Virol. 1994;68(11):7575-7581

60. Liu Y, et al. A modified alpha-galactosyl ceramide for staining and stimulating natural killer T cells. JImmunol Methods. 2006;312(1-2):34-39. 